This item was submitted to Loughborough's Research Repository by the author.

Items in Figshare are protected by copyright, with all rights reserved, unless otherwise indicated.

\title{
Optimization of square microneedle arrays for increasing drug permeability in
} skin

PLEASE CITE THE PUBLISHED VERSION

http://dx.doi.org/10.1016/j.ces.2008.02.007

PUBLISHER

(C) Elsevier Ltd

VERSION

AM (Accepted Manuscript)

\section{PUBLISHER STATEMENT}

This work is made available according to the conditions of the Creative Commons Attribution-NonCommercialNoDerivatives 4.0 International (CC BY-NC-ND 4.0) licence. Full details of this licence are available at: https://creativecommons.org/licenses/by-nc-nd/4.0/

\section{LICENCE}

CC BY-NC-ND 4.0

\section{REPOSITORY RECORD}

Al-Qallaf, Barrak, and Diganta Bhusan Das. 2014. "Optimization of Square Microneedle Arrays for Increasing Drug Permeability in Skin”. figshare. https://hdl.handle.net/2134/16544. 


\title{
Optimization of Square Microneedle Arrays for increasing Drug Permeability in Skin
}

\section{Barrak Al-Qallaf ${ }^{1}$, Diganta Bhusan Das ${ }^{2 \text { * }}$}

1 Department of Engineering Science, Oxford University, Oxford OX1 3PG, UK

2 Department of Chemical Engineering, Loughborough University, Loughborough LE11 3TU, UK

Revised Manuscript Submitted for Publication in the journal:

\author{
Chemical Engineering Science
}

9 January 2008

*Author for correspondence (Email: D.B.Das@lboro.ac.uk) 


\title{
Optimization of Square Microneedle Arrays for increasing Drug Permeability in Skin
}

\author{
Barrak Al-Qallaf ${ }^{1}$, Diganta Bhusan Das ${ }^{2 *}$ \\ 1 Department of Engineering Science, Oxford University, Oxford OX1 3PG, UK \\ 2 Department of Chemical Engineering, Loughborough University \\ Loughborough LE11 3TU, UK
}

5

\begin{abstract}
$\underline{\text { Abstract }}$
Microneedles array is a new transdermal drug delivery technique designed to create holes in the epidermis and penetrate the stratum corneum, thus avoiding the high resistance of this barrier. Microneedles have been shown to increase the skin permeability of drugs with no or little pain. However, the skin permeability of epidermis while using microneedle arrays has yet to be fully studied. In some cases, microneedle and microneedle array designs which were developed based on certain criteria (e.g., material of the microneedles) have to be related to other criteria (e.g., drug permeability in skin, skin thickness, etc). Therefore, in order to determine the optimum design of the microneedle arrays, the effect of different factors (e.g., number of the microneedle, surface area of the patch, etc) along with skin permeability by using microneedles should be determined accurately. In this work, an optimization framework for transdermal delivery of high molecular weight drug from microneedle is presented. The outputs of this framework have allowed us to identify the optimum design of various microneedles. Data from this optimization algorithm is then used to predict skin permeability of high molecular weight injected into the skin from a microneedle system. The effect of the optimized micro-needles on blood drug concentration has been determined. The outcome of this study is useful to propose an optimum design based on different measurement (e.g., variation of skin thickness) for transdermal delivery of drugs.
\end{abstract} 15 20

Keywords:

Microneedle arrays, Diffusion, Transdermal drug delivery, Optimisation, Mathematical 35 modelling, Mass transfer

*Author for correspondence (Email: D.B.Das@lboro.ac.uk; Tel: 00441509 222509) 


\section{Introduction}

In order to overcome the barrier function of the stratum corneum (i.e., the outer layer of skin), several attempts have been made to develop techniques for transdermal drug delivery. These include, e.g., electroporation (Sen et al., 2002), phonophoresis (Mitragotri et al., 1995), sonophoresis (Merino et al., 2003), chemical enhancers (Williams and Barry, 2004) and microneedles (Kim and Lee, 2007). One of the most recent methods is the application of microneedle arrays which combine the concepts of drug delivery across the skin using patches and the hypodermic injections. The working principle of the microneedle arrays has been discussed in a number of previous studies (Prausnitz, 2004; Al-Qallaf et al. 2007), etc. In short, this involves insertion of microneedles into skin so that they penetrate the stratum corneum and reach the viable epidermis. Since their first fabrication (e.g., Henry et al., 1998), microneedle designs with different geometries have been proposed as shown in Table 1. They are available as both solid and hollow microneedles made of glass (Martanto et al., 2006), silicon (Wilke and Morrissey, 2007), polymer (Sammoura et al., 2007; Park et al., 2007), titanium (Parker et al., 2007), metal (Kim and Lee, 2007), etc. The microneedles can also vary according to their tip shape, e.g.,, volcano like, micro-hypodermis and snake-fang design (Mukerjee et al., 2004) or the overall shape, e.g., pyramidal, spiked, candle-like and spear-shaped structure (Shikida et al., 2004). A review of different microneedle arrays being used for transdermal drug delivery has been carried out recently by Teo et al. (2006).

Although there has been an increase of up to three orders of magnitude in drug permeability in skin by using microneedles of various types and geometries, generally skin permeability has not been considered as a critical parameter in most previous studies. Skin permeability is a parameter that represents the path length of a solute across a given skin thickness over unit time (Environmental Protection Agency, 1992). The permeability of skin has been reported as a key factor that determines the efficiency of transdermal drug delivery process (Wilke et al., 2006). To deliver drugs across human skin for any medical reasons, the transport of drugs needs to be enhanced. One way to achieve this is by increasing skin permeability by artificial means which reduces the resistance of skin barrier to enhance the delivery of drugs. As expected, this necessitates knowing various factors that affect skin permeability when using microneedle arrays. In principle, skin permeability can be increased as a result of optimum microneedle dimensions. However, it is difficult to reach 
an optimum design without understanding the transport and mechanical properties of skin, e.g., skin permeability (Zahn et al., 2005).

In the literature, different approaches have been proposed to predict skin permeability across stratum corneum which are mostly applicable for low molecular weight compounds, 75 see, e.g., Wilschut et al. (1995) for a review of these approaches. In these approaches, the stratum corneum is assumed to be the rate limiting layer and the resistance of the drug transport provided by the viable skin is ignored (McCarley and Bunge, 2001). In the present context, the resistance of the stratum corneum is overcome by insertion of the microneedle and the rate limiting barrier of skin is the viable skin. Consequently, most of these approaches are not directly applicable. It must be pointed out that a number of attempts have been made already to evaluate skin permeability when using microneedle arrays. Wu et al. (2006) obtained a relationship between the number of bores and skin permeability using macroneedles instead of microneedles. They also found a relationship between molecular weight of macromolecules and skin permeability for hairless rat's skin. Another relationship between skin permeability and high molecular weight compounds was observed for hairless rat skin (Wu et al., 2007). However, both of these attempts used animal skin and not human skin. Also, these approaches did not consider the geometry of microneedles (e.g., number of microneedle, microneedle radius, etc) while evaluating skin permeability.

Recently, there has been an interest to investigate the influence of different variables related to the microneedles to reach optimum microneedle design and, hence, improve the transdermal drug delivery using microneedle arrays. Many relevant factors have been considered to formulate an optimized microneedle array system, including the mask shape of the microneedle, location of the microneedle hole, the microneedle tip radius, etc. Wilke and Morrissey (2007) present a method to optimize the mask shaped microneedles for three different shapes. They conclude that the square mask shape has the optimum shape compared to other shapes (e.g., diamond and circular). Khumpuang et al. (2007) have considered the optimum locations for various microneedle holes. The microneedle tip radius has been optimized to improve the tip sharpness by Teo et al. (2006). Whatever may be the aim of these studies, the ultimate aim is to deliver a quantity of a given drug in an effective manner to avoid any problems that may appear (e.g., damaging the liver, low absorption, etc) (Perennes et al., 2006). Recently, other questions have appeared related to 
optimisation of the microneedle arrays, e.g., how to make the needle diameters as small as possible so as to prevent bacteria and other foreign particles from entering into skin through the holes (Meidan and Michniak, 2004).

Our previous study considered the effects of various parameters (e.g., microneedle length, duration of application, etc) influencing the drug concentration in blood (Al-Qallaf et al., 2007). It carried out a sensitivity study which allowed identifying the important parameters for this paper. In this study, we present a framework developed specifically to design optimum microneedle arrays (e.g., number of microneedles, microneedle radius, etc) for transdermal drug delivery with a view to increase drug permeability in skin, called skin permeability hereafter. The framework includes the center-to-center spacing (pitch) of the microneedles to avoid any overlapping of the microneedle upon insertion into skin. The developed framework considers both solid and hollow microneedles which expand the scope of the current literature on microneedles for transdermal drug delivery. Another major goal of our study is to provide quantitative analysis of in vitro skin permeation when using microneedles by studying theoretically the influence of microneedle geometry on skin permeability. To achieve our objectives, an optimization algorithm based on java program has been developed in this work. A preliminary version of this optimization algorithm was presented by Al-Qallaf and Das (2007). In this work, we expand the range of geometrical parameters such as microneedle radius, surface area of microneedles etc, from what are available in the current literature (Al-Qallaf and Das, 2007) with the main aim to optimise these parameters. Skin permeability has been correlated to the variation of skin thickness depending on anatomical region and sex; whereas in our previous work (AlQallaf and Das, 2007) the variation of skin thickness was based on age and race. It is shown that correlation for predicting skin permeability of viable epidermis for high molecular weight can be developed which are envisaged to help design of the drug delivery devices. A relationship is presented between skin permeability and diffusion coefficient for the optimum of both the solid and hollow microneedles for various drugs. Previously obtained results (Al-Qallaf et al., 2007) of the maximum blood concentration are combined with the current results to demonstrate the optimum microneedle design.

\section{Methodology}

\subsection{Theoretical Model}


The developed framework is based on a simple theoretical in vitro model for calculating skin permeability (McAllister et al., 2003):

$$
\mathrm{K}=\mathrm{f} \frac{\mathrm{D}}{\mathrm{L}_{\mathrm{h}}}
$$

Where $\mathrm{K}$ is skin permeability of drugs, $\mathrm{f}$ is the fractional skin area after insertion by microneedles, $\mathrm{D}$ is the effective diffusion coefficient of drugs and $\mathrm{L}_{\mathrm{h}}$ is the length of the hole in skin. The effective diffusion coefficient (D) is often calculated using the StokesEinstein equation, if experimental data are not available (Poling et al., 2001). It must be pointed out that the hole length $\left(\mathrm{L}_{\mathrm{h}}\right)$ represents the epidermis thickness $(\mathrm{h})$ in case of solid microneedles, while this represents the microneedle length $(\mathrm{L})$ in case of hollow microneedles. This is because the drug molecules do not move through the microneedle itself in case of solid microneedle but traverse through various disruptions in the skin (i.e. epidermis) from the donor compartment (i.e., patch) to the receiver compartment (e.g., blood flow). On the other hand, when the molecules move through their bores in case of hollow microneedle, the path length represents the microneedle length as shown in Fig. 1. To develop the theoretical model, the following assumptions are made:

(a) One-dimensional transport of injected drug molecules (Lv et al., 2006).

(b) Viable epidermis is a homogenous medium.

(c) The drug injected by either solid or hollow microneedles is delivered into two parts. The first part is the epidermis and the second part is the dermis where the drug is absorbed into blood vessel. The sink condition (100\% absorption) occurs at the interface between the epidermis and dermis.

When the microneedles are inserted, a cylindrical shaped hole is obtained with radius (R), which refers to the microneedle radius (R), and annular gap width (W) between two holes. 160 The shape of the microneedle hole in the skin is conical if observed from the side. However, our assumption of the cylindrical shape of the microneedle hole in skin relates to top view, as shown in Figure 1. This has also been experimentally observed using scanning electron microscopy (McAllister et al., 2003). The fractional skin area when the microneedles are inserted is given as:

$$
\mathrm{f}=\mathrm{n}^{2} \pi \frac{(\mathrm{R}+\mathrm{W})^{2}-\mathrm{R}^{2}}{\mathrm{~A}}
$$

Where $\mathrm{n}$ is the total number of microneedles for a given patch, $\mathrm{R}$ is the microneedle radius, $\mathrm{W}$ is the annular gap width (W) and $\mathrm{A}$ is the surface area of the patch. As mentioned before, we want to be able to increase skin permeability by optimizing the dimensions of 
the microneedles. Therefore, equation (2) is adopted as our main governing equation for optimization.

The annular gap width $(\mathrm{W})$ is defined as a function of microneedle radius $(\mathrm{R})$ as follows:

$$
\mathrm{W}=\varepsilon \mathrm{R}
$$

Where $\varepsilon$ is a dimensionless parameter for the ratio of annular gap width over microneedle radius.

\subsection{Formulation of Optimization Function}

We assume that the patch is a square patch, where the numbers of microneedles $\left(n^{2}\right)$ are $n$ by $n$ (the number of microneedles per row). As $L_{h}, D$ and $\pi$ are constants, equation (2) can 180 be reformulated as:

$$
g=c \frac{n^{2} R^{2}}{A}
$$

Where $\mathrm{c}=\varepsilon(\varepsilon+2)$

In equation (4), c is dimensionless constant. Rewriting equation (4),

$$
g=\frac{n^{2} R^{2}}{A}
$$

Such that:

$$
\begin{aligned}
& \mathrm{n}_{\text {min }} \leq \mathrm{n} \leq \mathrm{n}_{\text {max }} \\
& \mathrm{R}_{\text {min }} \leq \mathrm{R} \leq \mathrm{R}_{\text {max }} \\
& \mathrm{A}_{\text {min }} \leq \mathrm{A} \leq \mathrm{A}_{\text {max }}
\end{aligned}
$$

From the first investigation of function (g), it is obvious that g reaches its highest value at maximum $\mathrm{n}$ and $\mathrm{R}$ and minimum A. However, a careful study of the square patch as shown in Fig. 2 revealed the need of considering another physical parameter which is the pitch $\left(\mathrm{P}_{\mathrm{t}}\right)$, the distance of centre-to-centre between two adjacent microneedles. This new constraint is given as:

$$
\mathrm{P}_{\mathrm{t}} \geq \alpha \mathrm{R}
$$

Where $\alpha>2.0$ (i.e., $\alpha$ is the aspect ratio of pitch over microneedle radius). To calculate the pitch, we define that in a given row of an array, the total distance for this row $(\mathrm{X})$ is given as:

$$
\mathrm{X}=\mathrm{nP}_{\mathrm{t}}
$$


Therefore, the surface area of a square patch is:

$$
\mathrm{A}=\mathrm{n}^{2} \mathrm{P}_{\mathrm{t}}{ }^{2}
$$

or,

$$
\mathrm{P}_{\mathrm{t}}=\frac{\sqrt{\mathrm{A}}}{\mathrm{n}}
$$

Equation (10) and (12) are combined to yield a new constraint for optimisation as:

$$
\frac{\sqrt{\mathrm{A}}}{\mathrm{n}} \geq \alpha \mathrm{R}
$$

\subsection{Governing Equations for Drug Transport in Skin}

The transient drug transport in skin tissue is expressed by Fick's second law as:

$$
\frac{\partial \mathrm{C}}{\partial \mathrm{t}}=\mathrm{D} \frac{\partial^{2} \mathrm{C}}{\partial \mathrm{x}^{2}}
$$

Where $\mathrm{C}$ is the drug concentration, $\mathrm{D}$ is the diffusion coefficient, $\mathrm{t}$ is time and $\mathrm{x}$ is the distance in a given skin layer. The initial boundary condition for solving equation (14) is given by the following equation, where the initial drug concentration in skin is set to zero:

$$
\mathrm{C}=0 \quad \text { at } \quad \mathrm{L}<\mathrm{x}<\mathrm{h}(\mathrm{t}=0)
$$

At the tip of the microneedle, the drug concentration is:

$$
\mathrm{C}=\mathrm{C}_{\mathrm{S}} \quad \text { at } \quad \mathrm{x}=\mathrm{L} \quad\left(0<\mathrm{t} \leq \mathrm{t}_{\mathrm{a}}\right)
$$

At the bottom of the skin epidermis, the concentration of the drug is:

$$
\mathrm{C}=0 \quad \text { at } \quad \mathrm{x}=\mathrm{h} \quad(0<\mathrm{t})
$$

Where, $\mathrm{C}_{\mathrm{s}}$ is the drug concentration at the tip of microneedle, $\mathrm{L}$ is the microneedle length, $\mathrm{t}_{\mathrm{a}}$ is the duration of application of the microneedles array and $\mathrm{h}$ is the epidermis thickness (i.e., distance to blood vessel). At $\mathrm{x}=\mathrm{h}$, the concentration of the drug is assumed to be zero (sink condition), as the drug has been up taken by dermal microcirculation (100\% absorbed).

The drug concentration in blood after imposing the transdermal drug delivery is given by one-compartmental pharmacokinetic model (Al-Qallaf et al., 2007; Tojo, 2005):

$$
\mathrm{V}_{\mathrm{b}} \frac{\mathrm{dC}_{\mathrm{b}}}{\mathrm{dt}}=\left(\frac{\mathrm{dQ}}{\mathrm{dt}}\right) \mathrm{S}_{\mathrm{a}}-\mathrm{K}_{\mathrm{e}} \mathrm{C}_{\mathrm{b}} \mathrm{V}_{\mathrm{b}}
$$


Where, $K_{e}$ is the elimination rate constant from the blood compartment, $d Q / d t$ is the penetration rate of drug through the skin, $S_{a}$ is the surface area of the delivery system (i.e., patch of microneedles), $V_{b}$ is the volume of distribution in the blood, $C_{b}$ is the drug concentration in the blood.

\subsection{Method of solution}

The optimization equation (6) and the constraint equations (7-9) and (13) were implemented and solved using an optimization model (Fig. 3). The optimization model is based on an in-house java program which searches the whole space of a possible solution based on the given limitations (constraints). The algorithm determines each value of the optimization function (g) at every point in a given space until it finds the optimum of (n, R, A) corresponding to the highest value of (g). The main idea of this framework is to iterate through the whole space of the parameters (i.e., n, R, A) using three nested loops. Moreover, in order to do this iteration, a scale (step size) must be defined by the user for each parameter as shown in Table 1. This iteration continues until the program finds the points representing the maximum value of $\mathrm{g}$, provided the geometrical conditions are fulfilled. The optimization model employs a java swing program to carry out the above mentioned procedure which is explained in the flowchart in Fig. 4.

The governing equations (14-18) were implemented and solved using the software, SKINCAD ${ }^{\circledR}$ (Biocom Systems, 2006). The mathematical framework of this software (i.e., SKINCAD ${ }^{\circledR}$ ) has been explained previously by Al-Qallaf et al. (2007) and is not discussed here.

\section{Results and Discussions}

We begin the discussions by presenting typical results of microneedle systems optimization for both solid and hollow microneedles with a view to demonstrate the developed optimisation framework. Table 2 shows some results of the developed program for the input parameters in Table 1. As mentioned before, our approach of optimization involves developing a method to provide optimum microneedle design with different geometries for solid and hollow microneedles. The results (Table 1) show that both solid and hollow microneedles reach their maximum optimization function $(\mathrm{g})$ at a value of $\approx 0.06$. To illustrate this optimization process in more details, various parameters (e.g., number of microneedles per row, microneedle radius, etc) have been optimized and analysed to 
provide better understanding of their influences in the optimization function (g), and hence, the design of microneedle.

\subsection{Optimization of Surface Area of Patch}

There have been many different sizes of both solid and hollow microneedles surface areas since their first manufacture. As expected, it is noticed that the transdermal drug delivery for a given amount of drug is constrained by the surface area of microneedle arrays (e.g., Gill and Prausnitz, 2007). This suggests the necessity to consider and optimise the surface area of patch while designing the array system of microneedles. As shown in equation (6), the surface area of patch has an inverse relationship with the optimization function (g). For the purpose of this section, we have carried our simulations to evaluate the optimum surface area of square patch for given number of microneedles per row (n) for both solid and hollow microneedles (Fig. 5). Our optimization program suggests that the optimum patches for solid and hollow microneedles for the input parameters in Table 1 are when the number of microneedles per row (n) equal 20 and 13, respectively. The optimum surface area of the patch is obtained for the highest value of the optimization function (g). This is because in cases of higher values of g, the transdermal drug transport is enhanced due to increased skin permeability. Fig. 5 shows that for the parameters in Table 1, the highest value of the optimization function $(\mathrm{g})$ is reached when the surface area of patch and microneedle radius equal $0.04 \mathrm{~cm}^{2}$ and $0.0025 \mathrm{~cm}$, respectively, in case of solid microneedles. On the other hand, in case of hollow microneedles, the highest value of optimization function $\mathrm{g}$ is reached when the surface area of patch and microneedle radius equal $0.53 \mathrm{~cm}^{2}$ and $0.014 \mathrm{~cm}$, respectively.

\subsection{Optimization of Microneedle Radius}

The radius of microneedles has a significant ability to increase the permeability of the skin. In a previous study, the transdermal drug delivery using solid and hollow microneedles was studied for different microneedle radius by Teo et al. (2005). By using two different radii, $50 \mu \mathrm{m}$ and $150 \mu \mathrm{m}$, Teo et al. (2005) showed an increase of flux by 10 times for the second radius. This illustrates that microneedle radius is an important dimension to be optimized while designing microneedle arrays. To understand the effect of microneedle radius on the optimization function g, and hence determine optimum microneedle radii, we have carried out simulations for both solid and hollow microneedles as shown in Fig. 6. The figure shows the optimum microneedle radius for the parameters in Table 1 . It seems that the 
optimum radii for solid and hollow microneedles are $0.0025 \mathrm{~cm}$ and $0.014 \mathrm{~cm}$, respectively, for these parameters. We define the optimum value when the highest value of $g$ function is reached. This is because we are seeking the maximum skin permeability and hence, the maximum values of $g$ function. On the other hand, the suboptimum case is defined as the lowest value of $g$ function. The results suggest that optimizing microneedle radius and hence, relating it to skin permeability is valuable for enhancing the performance of microneedles.

\subsection{Optimization of the number of microneedles per row}

A number of different microneedle designs that vary in the total number of microneedles have appeared in the literature for both solid and hollow microneedles (Table 1). In some cases, the number of microneedles is related to the surface area of patch which is defined as 'microneedle density'. The influence of the total number of microneedles has been studied experimentally by Park et al. (2005). They have changed the total number of microneedles for two model drugs (i.e., calcein and bovine serum albumin (BSA)). The results show that when the number of microneedles equals 100, skin permeability increases four fold as compared to another design where the number of microneedles is 20 for the model drugs (Park et al., 2005). The efficiency of transdermal drug delivery has been shown to improve by increasing the number of microneedles (Stoeber and Liepmann, 2005). In general, a high microneedle density is needed in order to increase the penetration efficiency (Shikida et al., 2006).

Although the influence of number of microneedles on the performance of the microneedles has been addressed before, we still need to consider how to optimize the number of microneedles in a given patch. The implications of changing the number of microneedles per row (n) on the optimization function (g) for both optimum/suboptimum microneedle designs is shown in Fig. 7. The optimum designs have significant increase in skin permeability indicated by higher values of the optimization function (g). The optimum designs offer variety of different microneedle geometries based on a given criterion, e.g., cost of fabrication, etc. Referring to Fig. 8, it is clear that the optimization function (g) starts to reduce when it reaches the highest value (i.e., $g \approx 0.06$ ) in all cases. 
The optimization function for both solid and hollow microneedles varies nonlinearly with surface area of patch when changing the optimum number of microneedle per row with their optimum microneedle radius.

Fig. 9 illustrates the importance of considering the optimum microneedle geometries (i.e., microneedle radius (R), number of microneedles per row (n)) for increasing skin permeability. For example, the value of $g$ for the optimum microneedle (i.e., $n=20$, $\mathrm{R}=0.0025 \mathrm{~cm}$ ) is five times more than the suboptimum design (i.e., $\mathrm{n}=10, \mathrm{R}=0.0025 \mathrm{~cm}$ ) for solid microneedles. This figure suggests that reaching the optimum value for a given geometry (i.e., microneedle radius) is not always the best approach to increase skin permeability. It is noticed that the optimization function (g) depends on all the input parameter which are again connected to one another. Therefore, in order to reach the highest value of our optimization function, the input parameters must be optimized too.

\subsection{Optimization of the Aspect Ratio $(\alpha)$}

The aspect ratio of the microneedle geometry has been defined in different ways so far. For example, Huang and Fu (2007) define it as the base over tip diameter. Park et al. (2005) describe it as the ratio of microneedle length to tip diameter. In other case, the aspect ratio refers to the length over width (Davis et al., 2005) of the microneedles. The ratio of needle height to base diameter has been called as the aspect ratio too (Wilke et al., 2005). In our work, the aspect ratio $(\alpha)$ relates to the ratio of the center-to-center distance between two microneedles (pitch) to the microneedle radius (R). In general, this parameter should be greater than 2.0 so that an overlapping between any microneedles does not occur. Further, if the pitch is too small $(<2.0)$, then the needles are placed too close to one another which may prevent them from pain free penetration of the skin due to their mechanical strengths and reaching the targeted depth (e.g., see Miyano et al., 2005).

Fig. 10 and 11 depict the influences of the aspect ratio $(\alpha)$ for both solid and hollow microneedles. Fig. 10 shows that in some cases the aspect ratio has no obvious influence on the optimum microneedle radius or pitch. This is clear in case of hollow microneedles of aspect ratio equal 25 and the microneedle radius is $0.004 \mathrm{~cm}$. On the other hand, in case of other aspect ratios, the optimum pitch for both solid and hollow microneedles varies linearly with microneedle radius. Fig. 11 reveals how the aspect ratio of solid and hollow microneedles influences the optimization function. The highest value of the optimization 
function for solid and hollow microneedles occurs for an aspect ratio of 3.1 and 2.7, respectively. This figure also demonstrates that for a given aspect ratio, changing the number of microneedles per row does not affect the optimization function significantly. Therefore, it seems that the optimization function is more sensitive to aspect ratio than the number of microneedles. It also seems that for a given number of microneedles, a smaller aspect ratio would increase the optimization function and hence, skin permeability.

\subsection{Effect of the Skin Thickness}

As well known, skin thickness can vary according to age, race, anatomical region and sex (Lee and Hwang, 2002). See, for example, Artz et al. (1979) who show that the ratio of epidermis to dermis has a significant variation from one anatomical region to another. Skin thickness therefore can play an important role as a barrier against any injected drugs. In a previous work, Al-Qallaf and Das (2007) have studied the influence of epidermis thickness of various anatomical regions and sex on skin permeability for various drugs. In this work, we evaluate the effect of epidermis thickness for various age groups and race on drug permeation in skin. There is a strong evidence of the changes in the function and structure of the human skin as human age (Fenske and Lober, 1986). For example, a comparison has been done between the thicknesses of the Korean skin with another race (Caucasian) (Lee and Hwang, 2002). These results show that the thickness of the epidermis is lower in Caucasians than in Koreans. These studies clearly suggest that the skin thickness should be considered when designing microneedles. As explained previously, the path length of skin disruption made by solid microneedles represents the effective diffusion length (i.e., thickness of the epidermis) and there is an inverse relationship between the epidermis thickness (h) and skin permeability (K) (equation 1).

The dependency of the thickness of epidermis (h) for various age groups (Artz et al., 1979) on skin permeability $(\mathrm{K})$ for calcein as a model drug is shown in Fig. 12. Although calcein has a low molecular weight allowing it to diffuse across stratum corneum, calcein has been adopted in many papers for transdermal drug delivery using microneedles (Gill and Prausnitz, 2007; Park et al., 2006; Wang et al., 2006; Miyano et al., 2005; Park et al., 2005; Teo et al., 2005; McAllister et al., 2003; Henry et al., 1998). The skin permeability of calcein without/with using microneedles is $1 \mu \mathrm{g} / \mathrm{cm}^{2} / \mathrm{hr}$ and $50 \mu \mathrm{g} / \mathrm{cm}^{2} / \mathrm{hr}$, respectively (Xie et al., 2005). In another study, the skin permeability of calcein was determined to be 
$1 \times 10^{-7} \mathrm{~cm} / \mathrm{h}$ without microneedles and $1 \times 10^{-2} \mathrm{~cm} / \mathrm{h}$ with microneedles (Henry et al., 1998). Calcein is therefore a very suitable model drug which allows one to identify the effectiveness of microneedle. However, we must point out that calcein does not necessarily diffuse across stratum corneum. For example, Kolli and Banga (2007) observe that calcein does not diffuse across the intact stratum corneum (i.e., follicular pathway and appendages). These studies also prove the necessity of considering calcein as a model drug for transdermal drug delivery using microneedles. In other words, in cases where calcein 400 does not necessarily diffuse through stratum corneum, one may use microneedles as a transdermal drug delivery method.

Fig. 12 shows the influence between optimum/suboptimum designs on skin permeability. As expected, there is a significant increase in skin permeability for the optimum design 405 compared with the suboptimum design. For example, the difference in skin permeability for a given microneedle between the epidermis thickness of age group (0-5) and age group (1115) proves the necessity of considering the skin thickness. Fig. 13 shows the effect of the epidermis thickness of different races (i.e., Korean and Caucasian) on skin permeability. The optimized design shows significant increase when compared with the suboptimum design for a given race. For example, in case of Caucasian skin the skin permeability of the optimum design increases 13 times more than the suboptimum design. These results are consistent with our claim to consider the classification of skin thickness when designing microneedle arrays.

\subsection{Effect of Skin Permeability}

The geometries of our optimized configuration (solid microneedles) were compared with another design (McAllister et al., 2003) for different model drugs. This comparison is particularly useful to illustrate the efficiency of the developed framework. Fig. 14 reflects the influences of two designs for various model drugs on skin permeability before and after

applying optimised microneedle systems. As expected, skin permeability dramatically increases for different drugs when using the optimum design. The results show that skin permeability reaches its highest value when calcein is delivered. This is obviously because calcein has the highest diffusion coefficient $\left(6 \times 10^{-6} \mathrm{~cm}^{2} / \mathrm{s}\right)$ (McAllister et al., 2003) among the model drugs and the lowest molecular weight (623 Da) (Nishimura and Lemasters, 2001). In an attempt to generalize the influence of our optimized design on skin 
permeability across human skin, a relationship was formulated between skin permeability (K) and diffusion coefficient (D) for the selected model drugs as shown in Fig. 15. It seems there is a linear correlation for both solid and hollow microneedles. In case of solid microneedles, the correlation is given by,

430

$$
\mathrm{K}=1.14 \times \mathrm{D}-3 \times 10^{-22} \mathrm{~cm} / \mathrm{s} \quad 6.5 \times 10^{-8}<\mathrm{D}<5 \times 10^{-6}
$$

Where, epidermis thickness (h) is $0.005 \mathrm{~cm}$, the total number of microneedles $\left(\mathrm{n}^{2}\right)$ is 400 , microneedle radius $(\mathrm{R})$ is $0.0025 \mathrm{~cm}$, surface area of patch $(\mathrm{A})$ is $0.04 \mathrm{~cm}^{2}$ and pitch $\left(\mathrm{P}_{\mathrm{t}}\right)$ is $0.01 \mathrm{~cm}$. In case of hollow microneedles, the correlation is given by the following relationship:

$$
\mathrm{K}=1.98 \times \mathrm{D}-6 \times 10^{-22} \mathrm{~cm} / \mathrm{s} \quad 6.5 \times 10^{-8}<\mathrm{D}<5 \times 10^{-6}
$$

Where, the microneedle length $(\mathrm{L})$ is $0.005 \mathrm{~cm}$, the total number of microneedles $\left(\mathrm{n}^{2}\right)$ is 169 , microneedle radius $(\mathrm{R})$ is $0.014 \mathrm{~cm}$, surface area of patch (A) is $0.53 \mathrm{~cm}^{2}$ and pitch $\left(\mathrm{P}_{\mathrm{t}}\right)$ is $0.056 \mathrm{~cm}$.

In a previous study, we have shown the effect of microneedle dimensions (i.e., surface area of patch) on blood drug concentration. In Fig. 16, we have plotted skin permeability with maximum insulin concentration (steady-state) in blood for the optimum hollow microneedles $(n=13)$ to determine the intercept point. This intercept point shows the optimum design (i.e., surface area of patch $(A) \approx 0.45 \mathrm{~cm}^{2}$ ) of hollow microneedles. In some cases, where the blood drug concentration and skin permeability are considered in manufacturing microneedles, this graph might be useful.

This shows that this intercept occurs at a patch surface area of $\approx 0.45 \mathrm{~cm}^{2}$ corresponding to skin permeability and maximum insulin concentration in blood of $5.2 \times 10^{-7} \mathrm{~cm} / \mathrm{s}$ and $7.6 \times 10^{-5} \mu \mathrm{g} / \mathrm{mL}$, respectively. The input parameters of this figure are shown in Table 3 . This result is important in some cases where both the skin permeability and blood drug concentration are considered.

\section{Conclusion}

A framework has been presented in this paper to optimize the microneedle dimensions used in transdermal drug delivery with a view to increase skin permeability. The paper provides different optimum designs of solid and hollow microneedles with various dimensions. The variation of microneedle geometries (e.g., total number of microneedles, microneedle 
radius, pitch, etc) of the optimum design allows one to choose dimensions according to

one's need. The results presented in this paper suggest that the pitch has more priority than microneedle radius when designing microneedles. The influence of skin thickness with its classifications (i.e., age group, race) on skin permeability using microneedle systems has been studied. We have shown that the skin thickness is major factor that must be considered in designing microneedles. This suggests that for designing microneedle arrays, optimizing various transport parameters as well as physical dimensions of the system enhance efficiency of transdermal drug delivery techniques.

These relationships between diffusion coefficient and skin permeability enable prediction of drug permeation across human skin to deliver low/high molecular weight drug using 470 microneedles. The maximum blood concentration of insulin on hollow microneedle was determined, and plotted against skin permeability. These data were useful in case of considering both skin permeability and blood drug concentration to determine the optimum surface area of the patch. The study presented in this paper is expected to be suitable to overcome the problems arising for drugs with low skin permeability.

\section{Acknowledgment}

The authors would like to thank MOI (Ministry of Interior), Kuwait for their funding of this work. The comments of two anonymous referees which helped to improve the content of this paper are gratefully acknowledged.

\section{References}

Al-Qallaf, B., Das, D.B., Mori, D., Cui, Z.F. (2007). Modelling transdermal delivery of high molecular weight drugs from microneedle systems. Journal of Philosophical Transactions of the Royal Society of London Series A-Mathematical Physical and Engineering Science, 365: 2951-2967.

Al-Qallaf, B., Das, D.B., (2007). Optimizing microneedle arrays to increase skin permeability for transdermal drug delivery. Proceedings of Interdisciplinary Transport Phenomena V (ITP2007): Fluid, Thermal, Biological, Materials and Space Sciences, 490 October 12-19, Bansko, Bulgaria. 
Artz, C.P., Moncrief, J.A., Pruitt, B.A., (1979). Burns: a team approach. Saunders, Philadelphia, pp. 22-24.

495

Biocom system, Inc., (2006). SKIN-CAD ${ }^{\circledR}$. Simulator for skin pharmacokinetics. Biocom system, Inc., Fukuoka, Japan.

Davis, S.P., (2003). Hollow microneedles for molecular transport across skin. Ph.D. Thesis. Georgia Institute of Technology, USA.

Davis, S.P., Martanto, W., Allen, M.G., Prausnitz, M.R., (2005). Hollow metal microneedles for insulin delivery to diabetic rats. IEEE Transactions on Biomedical Engineering, 52(5), 909-915.

Environmental Protection Agency. (1992). Risk assessment forum. Guideline for exposure $\begin{array}{llll}\text { assessment (FRL-4129-5). Washington } & \text { D.C. }\end{array}$ http://www.epa.gov/ncea/raf/pdfs/exposure.pdf.

Fenske, N.A., Lober, C.W., (1986). Structural and functional changes of normal aging skin. 510 Journal of the American Academy of Dermatology, 48, 571-585.

Gill, H.S., Prausnitz, M.R., (2007). Coated microneedles for transdermal delivery. Journal of Controlled Release, 117, 227-237.

Gui, L., Liu, J., (2005). Study on the heat and fluid transport inside the biological tissues subject to boiling saline-based tumor hyperthermic injection. Heat Transfer Engineering, 26, 73-84.

Henry, S., McAllister, D.V., Allen, M.G., Prausnitz, M.R., (1998). Microfabrication 520 microneedles: A novel approach to transdermal drug delivery. Journal of Pharmaceutical Sciences, 87(8), 922-925.

Huang, H., Fu, C., (2007). Different fabrication methods of out-of-plane polymer hollow needle arrays and their variations. Journal of Micromechanics and Microengineering, 17, 525 393-402. 
Kaushik, S., Hord, A.H., Denson, D.D., McAllister, D.V., Smitra, S., Allen, M.G., Prausnitz, M.R., (2001). Lack of pain associated with microfabricated microneedles. Anesthesia and Analgesia. 92, 502-504.

Khumpuang, S., Horade, M., Fujioka K., Kazuya, F., Sugiyama, S., (2007). Geometrical strengthening and tip-sharpening of a microneedle array fabricated by X-ray lithography. Microsystem Technologies, 13, 209-214.

Kim, K., Lee, J.B., (2007). High aspect ratio tapered hollow metallic microneedle arrays with microfluidic interconnector. Microsystem Technologies, 13, 231-235.

Kolli, C.S., Banga, A.K., (2007). Characterization of solid maltose microneedles and their use for transdermal delivery. Pharmaceutical Research, DOI: 10.1007/s11095-007-9350-0.

Lee, Y., Hwang, K., (2002). Skin thickness of Korean adults. Surgical and Radiologic Anatomy, 24, 183-189.

Lv, Y.G., Liu, J., Gao, Y.H., Xu, B. (2006). Modeling of transdermal drug delivery with a 545 microneedle array. Journal of Micromechanics and Microengineering, 16, 2492-2501.

Martanto, W., Moore, J.S., Couse, T., Prausnitz, M.R., (2006). Mechanism of fluid infusion during microneedle insertion and retraction. Journal of Controlled Release, 112, 357-361.

McAllister, D.V., Wang, P.M., Davis, S.P., Park J.H., Canatella, P.J., Allen, M.G., Prausnitz, M.R., (2003). Microfabricated needles for transdermal delivery of macromolecules and nanoparticles: fabrication methods and transport studies. Proceedings of the National Academy of Sciences of the United States of America, 100, 13755-13760.

McCarley, K.D., Bunge, A.L., (2001). Pharmacokinetics models of dermal absorption. Journal of Pharmaceutical Sciences, 90(11), 1699-1719.

Meidan, V.M., Michniak, B.B., (2004). Emerging technologies in transdermal therapeutics. American Journal of Therapeutics, 11, 312-316. 
Merino, G., Kalia, Y.N., Guy, R.H., (2003). Ultrasound enhanced transdermal transport. Journal of Pharmaceutical Sciences, 92, 1125-1137.

Mitragotri, S., Blankschtein, D., Langer, R., (1995). Ultrasound-mediated transdermal 565 protein delivery. Science, 269(5225), 850-853.

Miyano, T., Tobinaga, Y., Kanno, T., Matsuzaki, Y., Takeda, H., Wakui, M., Hanada, K., (2005). Sugar micro needles as transdermic drug delivery systems. Biomedical Microdevices, 7(3), 185-188.

Mukerjee, E.V., Collins, S.D., Issroff, R.R., Smith, R.L., (2004). Microneedle array for transdermal biological fluid extraction and in situ analysis. Sensors and Actuators, 114, 267-275.

575

Nishimura, Y., Lemasters, J.J., (2001). Glycine blocks opening of a death channel in cultured hepatic sinusoidal endothelial cells during chemical hypoxia. Cell Death \& Differentiation, 8, 850-858.

Park, J.H., Allen, M.G., Prausnitz, M.R., (2005). Biodegradable polymer microneedles: 580 fabrication, mechanics and transdermal drug delivery. Journal of Controlled Release, 104, 51-66.

Park, J.H., Allen, M.G., Prausnitz, M.R., (2006). Polymer microneedles for controlledrelease drug delivery. Pharmaceutical Research, 23(5), 1008-1019.

Park, J.H., Yoon, Y.K., Choi, S.O., Prausnitz, M.R., Allen, M.G., (2007). Tapered conical polymer microneedles fabricated using an integrated lens technique for transdermal drug delivery. IEEE Transactions on Biomedical Engineering, 54(5), 903-913.

Parker, E.R., Rao, M.P., Turner K.L., Meinhart, C.D., MacDonald, N.C., (2007). Bulk micromachined titanium microneedles. Journal of Microelectromechanical System, 16(2), 289-295. 
Perennes, F., Marmiroli, B., Matteucci, M., Tormen, M., Vaccari, L., Fabrizio, E.D., 595 (2006). Sharp beveled tip hollow microneedle arrays fabricated by LIGA and 3D soft lithography with polyvinyl alcohol. Journal of Micromechanics and Microengineering, 16, 473-479.

Poling, B.E., Prausnitz, J.M., O'Connell, J.P., (2001). The properties of gases and liquids. 600 McGraw-Hill, New York.

Prausnitz, M.R. 2004 Microneedles for transdermal drug delivery. Advanced Drug Delivery Reviews, 56, 581-587.

Sammoura, F., Kang, J.J., Heo, Y.M., Jung, T.S., Lin, L., (2007). Polymeric microneedle fabrication using a microinjection molding technique. Microsystem Technologies, 13, 517522.

Sen, A., Daly, M.E., Hui, S.W., (2002). Transdermal insulin delivery using lipid enhanced 610 electroporation. Biochimica ET Biophysica Acta, 1564, 5-8.

Shikida, M., Odagaki, M., Todoroki, N., Ando, M., Ishihara, Y., Ando, T., Sato, K., (2004). Non-photolithographic pattern transfer for fabricating arrayed three-dimensional microstructures by chemical anisotropic etching. Sensors and Actuators, 16, 264-271.

Shikida, M., Hasada, T., Sato, K., (2006). Fabrication of a hollow needle structure by dicing wet etching and metal deposition. Journal of Micromechanics and Microengineering, 16, 2230-2239.

Stoeber, B., Liepmann, D., (2005). Arrays of hollow out-of-plane microneedles for drug delivery. Journal of Microelectromechanical Systems, 14(3), 472-479.

Teo, M.A.L., Shearwood, C., Ng, K.C., Lu, J., Moochhala, S., (2005). In vitro and in vivo characterization of MEMS microneedles. Biomedical Microdevices, 7(1), 47-52. 
Teo, M.A.L., Shearwood, C., Ng, K.C., Lu, J., Moochhala, S., (2006). Transdermal microneedles for drug delivery applications. Materials Science and Engineering, 132, 151154.

Tojo, K., (2005). Mathematical models of transdermal and topical drug delivery, 2nd ed., Biocom Systems Inc., Japan.

Van Rossum, J. (1977). Kinetics of Drug Action, 3rd ed., Springer-Verlag, Berlin.

Verbaan, F.J., Bal, S.M., Van den Berg, D.J., Groenink, W.H.H., Verpoorten, H., Luttge, R., Bouwstra, J.A., (2007). Assembled microneedle arrays enhance the transport of compounds varying over a large range of molecular weight across human dermatomed skin. Journal of Controlled Release, 117, 238-245.

Wang, P.M., Cornwell, M., Hill, J., Prausnitz, M.R., (2005). Precise microinjection into skin using hollow microneedles. Journal of Investigative Dermatology, 126, 1080-1087.

Wilke, N., Mulcahy, A., Ye, S.R., Morrissey, A., (2005). Process optimization and characterization of silicon microneedles fabricated by wet etch technology. 645 Microelectronics Journal, 36, 650-656.

Wilke, N., Reed, M.L., Morrissey, A., (2006). The evolution from convex corner undercut towards microneedle formation: theory and experimental verification. Journal of Micromechanics and Microengineering, 16, 808-814.

Wilke, N., Morrissey, A., (2007). Silicon microneedle formation using modified mask designs based on convex corner undercut. Journal of Micromechanics and Microengineering, 17, 238-244.

Williams, A.C., Barry, B.W., (2004). Penetration enhancers. Advanced Drug Delivery Reviews, 56, 603-618. 
Wilschut, A., Ten Berge, W.F., Robinson, P.J., McKone, T.E., (1995). Estimating skin permeation: The validation of five mathematical skin permeation models. Chemosphere, 660 30, 1275-1296.

Wu, X.M., Todo, H., Sugibayashi, K., (2006). Effects of pretreatment of needle puncture and sandpaper abrasion on the in Vitro skin permeation of fluorescein isothiocyanate (FITC)-dextran. International Journal of Pharmaceutics, 316, 102-108.

Wu, X.M., Todo, H., Sugibayashi, K., (2007). Enhancement of skin permeation of high molecular compounds by a combination of microneedle pretreatment and iontophoresis. Journal of Controlled Release, 118, 189-195.

Xie, Y., Xu, B., Gao, Y., (2005). Controlled transdermal delivery of model drug compounds by MEMS microneedle array. Nanomedicine: Nanotechnology, Biology, and Medicine, 1, 184-190.

Zahn, J.D., Hsieh, Y.C., Yang, M., (2005). Components of an integrated microfluidic device for continuous glucose monitoring with responsive insulin delivery. Diabetes Technology \& Therapeutics, 7(3), 536-545. 
List of Tables

Table 1. The input of geometrical parameters used in this work for optimizing solid and hollow microneedles arrays.

Table 2. The output of the optimum parameters after applying our optimization model for both solid and hollow microneedles.

Table 3. The values of model parameters used in this work for analyzing the blood concentration of Insulin penetrated through the skin using our optimum microneedles arrays patch. 


\section{List of Figures}

Figure 1. The Schematic diagram of solid and hollow microneedles.

Figure 2. The Schematic diagram of a square patch of microneedle array (top view).

Figure 3. Graphical user interface of in-house Java program used for microneedles system optimization.

Figure 4. Algorithm used in Java program (Figure 2) for microneedles system optimization.

Figure 5. Influence of the surface area of the patch (A) of solid (dark points) and hollow (light points) microneedles on the optimization function (g), (number of microneedles per row $(\mathrm{n})=20,13$ for solid and hollow microneedles, respectively, aspect ratio $(\alpha)=4)$.

Figure 6. Influence of the microneedle radius (R) of solid (dark points) and hollow (light points) microneedles on the optimization function (g), (number of microneedles per row (n) =20, 13 for solid and hollow microneedles, respectively, aspect ratio $(\alpha)=4)$.

Figure 7. Influence of the optimum/suboptimum number of microneedles per row (n) for solid (dark points) and hollow (light points) microneedles on the optimization function (g) for parameters as shown in Table 2, (aspect ratio $(\alpha)=4)$.

Figure 8. Influence of the number of microneedles per row (n) for solid (dark points) and hollow (light points) microneedles with their optimum radii on the optimization function $(\mathrm{g})$ (aspect ratio $(\alpha)=4)$.

Figure 9. Influence of optimum/suboptimum number of microneedles per row (n) for solid (dark points) and hollow (light points) microneedles with their optimum/suboptimum radius on the optimization function (g) (aspect ratio $(\alpha)=4)$. 
Figure 10. Influence of the aspect ratio of pitch over microneedle radius $(\alpha)$ of solid (dark points) and hollow (light points) microneedles on the optimum pitch $\left(\mathrm{P}_{\mathrm{t}}\right)$ for various number of microneedles per row $(\mathrm{n})$.

Figure 11. Influence of the aspect ratio of pitch over microneedle radius $(\alpha)$ of solid (dark points) and hollow (light points) microneedles on our optimization function (g) for various number of microneedles per row (n).

Figure 12. Influence of epidermis thickness (h) of optimum/suboptimum numbers of microneedles per row (n) for solid microneedles for various groups age on skin permeability $(\mathrm{K})$.

Figure 13. Influence of epidermis thickness (h) of optimum/suboptimum numbers of microneedles per row (n) for solid microneedles for different races on skin permeability (K).

Figure 14. Influence of applying our optimization model in skin permeability (K) for different drugs (i.e., insulin is hexameric insulin, nano(25) and nano(50) are nanosphere particles with molecular radii of $25 \mathrm{~nm}$ and $50 \mathrm{~nm}$, respectively).

Figure 15. Relationship between skin permeability (K) and diffusion coefficient (D) of the optimum solid $\left(\mathrm{n}=20, \mathrm{R}=19 \mu \mathrm{m}\right.$ and $\left.\mathrm{A}=0.04 \mathrm{~cm}^{2}\right)$ and hollow $(\mathrm{n}=13$, $\mathrm{R}=14 \mu \mathrm{m}$ and $\mathrm{A}=0.53 \mathrm{~cm}^{2}$ ) microneedles for various drugs (i.e., calcein, insulin, BSA (bovine serum albumin), nano25 and nano50 (nanosphere particles with radii of $25 \mathrm{~nm}$ and $50 \mathrm{~nm}$, respectively)).

Figure 16. The optimum point (intercept) between skin permeability (K) and maximum blood drug concentration (Cb,max) of the optimum hollow microneedles $(\mathrm{n}=13$ and $\mathrm{R}=115 \mu \mathrm{m})$ with various surface area of patch for insulin as a model drug. 
Table 1. The input geometrical parameters used in this work for optimizing solid and hollow microneedles arrays (Al-Qallaf and Das, 2007)

\begin{tabular}{|c|c|c|c|c|}
\hline Parameters & Solid & Hollow & $\begin{array}{c}\text { Scaling } \\
\text { Parameters }\end{array}$ & References \\
\hline $\begin{array}{l}\text { Number of } \\
\text { Microneedles per } \\
\text { row: n (-) }\end{array}$ & $10^{\mathrm{d}} \leq \mathrm{n} \leq 20^{\mathrm{e}}$ & $4^{\mathrm{h}} \leq \mathrm{n} \leq 20^{\mathrm{a}}$ & 1 & $\begin{array}{l}\text { a. Kaushik et al. (2001) } \\
\text { b. Shikida et al. (2004) } \\
\text { c. Park et al. (2005) }\end{array}$ \\
\hline $\begin{array}{l}\text { Microneedle } \\
\text { Radius: R (cm) }\end{array}$ & $0.0025^{\mathrm{b}} \leq \mathrm{R} \leq 0.0075^{\mathrm{d}}$ & $0.004^{\mathrm{a}} \leq \mathrm{R} \leq 0.015^{\mathrm{g}}$ & 5 & $\begin{array}{l}\text { d. Teo et al. (2005) } \\
\text { e. Xie et al. (2005) }\end{array}$ \\
\hline $\begin{array}{l}\text { Surface area of } \\
\text { microneedles } \\
\text { array: } \mathrm{S}_{\mathrm{a}}\left(\mathrm{cm}^{2}\right)\end{array}$ & $0.04^{\mathrm{d}} \leq \mathrm{A} \leq 0.81^{\mathrm{c}}$ & $0.04^{\mathrm{d}} \leq \mathrm{A} \leq 0.56^{\mathrm{f}}$ & 0.01 & $\begin{array}{l}\text { f. Wu et al. (2007) } \\
\text { g. Khumpuang et al. (2007) } \\
\text { h. Verbaan et al. (2007) }\end{array}$ \\
\hline $\begin{array}{l}\text { Aspect ratio of } \\
\text { pitch over radius: } \\
\alpha(-)\end{array}$ & $2.7^{\mathrm{d}} \leq \alpha \leq 12^{\mathrm{c}}$ & $3.1^{\mathrm{a}} \leq \alpha \leq 25^{\mathrm{f}}$ & & \\
\hline
\end{tabular}


Table 2. The output of the optimum parameters after applying our optimization model for both solid and hollow microneedles.

\begin{tabular}{|c|c|c|c|c|c|c|c|c|c|}
\hline \multicolumn{5}{|c|}{ Solid Microneedles } & \multicolumn{5}{|c|}{ Hollow Microneedles } \\
\hline $\begin{array}{l}\text { Number of } \\
\text { Microneedles } \\
\text { per row: } n(-)\end{array}$ & $\begin{array}{l}\text { Microneedle } \\
\text { Radius: R } \\
\text { (cm) }\end{array}$ & $\begin{array}{l}\text { Surface area } \\
\text { of Patch: A } \\
\left(\mathrm{cm}^{2}\right)\end{array}$ & $\begin{array}{l}\text { Pitch: } P_{t} \\
(\mathrm{~cm})\end{array}$ & $\begin{array}{l}\text { Optimization } \\
\text { Function: g(-) }\end{array}$ & $\begin{array}{l}\text { Number of } \\
\text { Microneedles } \\
\text { per row: n (-) }\end{array}$ & $\begin{array}{l}\text { Microneedle } \\
\text { Radius: R } \\
\text { (cm) }\end{array}$ & $\begin{array}{l}\text { Surface area } \\
\text { of Patch: A } \\
\left(\mathrm{cm}^{2}\right)\end{array}$ & $\begin{array}{l}\text { Pitch: } P_{t} \\
(\mathrm{~cm})\end{array}$ & $\begin{array}{l}\text { Optimization } \\
\text { Function: g(-) }\end{array}$ \\
\hline 10 & 0.007 & 0.08 & 0.0283 & 0.06125 & 4 & 0.015 & 0.06 & 0.0612 & 0.06 \\
\hline 11 & 0.006 & 0.07 & 0.0241 & 0.06223 & 5 & 0.014 & 0.08 & 0.0566 & 0.06125 \\
\hline 12 & 0.0075 & 0.13 & 0.03 & 0.06231 & 6 & 0.015 & 0.13 & 0.0601 & 0.06231 \\
\hline 13 & 0.006 & 0.1 & 0.0243 & 0.06084 & 7 & 0.015 & 0.18 & 0.0606 & 0.06125 \\
\hline 14 & 0.0075 & 0.18 & 0.0303 & 0.06125 & 8 & 0.012 & 0.15 & 0.0484 & 0.06144 \\
\hline 15 & 0.006 & 0.13 & 0.024 & 0.06231 & 9 & 0.01 & 0.13 & 0.0401 & 0.06231 \\
\hline 16 & 0.006 & 0.15 & 0.0242 & 0.06144 & 10 & 0.009 & 0.13 & 0.0361 & 0.06231 \\
\hline 17 & 0.0055 & 0.14 & 0.022 & 0.06244 & 11 & 0.0085 & 0.14 & 0.034 & 0.06244 \\
\hline 18 & 0.005 & 0.13 & 0.02 & 0.06231 & 12 & 0.0135 & 0.42 & 0.054 & 0.06249 \\
\hline 19 & 0.006 & 0.21 & 0.0241 & 0.06189 & 13 & 0.014 & 0.53 & 0.056 & 0.0625 \\
\hline 20 & 0.0025 & 0.04 & 0.01 & 0.06250 & 14 & 0.013 & 0.53 & 0.052 & 0.0624 \\
\hline & & & & & 15 & 0.006 & 0.13 & 0.024 & 0.0623 \\
\hline & & & & & 16 & 0.0095 & 0.37 & 0.038 & 0.06244 \\
\hline & & & & & 17 & 0.0105 & 0.51 & 0.042 & 0.06248 \\
\hline & & & & & 18 & 0.009 & 0.42 & 0.036 & 0.06249 \\
\hline & & & & & 19 & 0.008 & 0.37 & 0.032 & 0.06244 \\
\hline & & & & & 20 & 0.008 & 0.41 & 0.032 & 0.06244 \\
\hline
\end{tabular}


Table 3. The values of model parameters used in this work for analyzing the blood concentration of Insulin penetrated through the skin using our optimum microneedles arrays patch.

\begin{tabular}{|l|c|c|}
\hline Parameters & $\begin{array}{c}\text { Model drug } \\
\text { (Insulin) }\end{array}$ & References \\
\hline $\begin{array}{l}\text { Duration for medication (calculation): } \mathrm{t}_{\mathrm{m}} \\
\text { (hour) }\end{array}$ & 8 & Al-Qallaf et al. (2007) \\
\hline $\begin{array}{l}\text { Duration of microneedles application: } \mathrm{t}_{\mathrm{d}} \\
\text { (hour) }\end{array}$ & 4 & Al-Qallaf et al. (2007) \\
\hline Surface area of microneedles array: A $\left(\mathrm{cm}^{2}\right)$ & Variable & - \\
\hline Thickness of viable epidermis: $\mathrm{h}_{\mathrm{v}}(\mathrm{cm})$ & 0.02 & Lee and Hwang (2002) \\
\hline Effective skin thickness: $\mathrm{h}_{\mathrm{e}}(\mathrm{cm})$ & 0.01 & - \\
\hline $\begin{array}{l}\text { Diffusion Coefficient in viable skin: } \mathrm{D}_{\mathrm{vs}} \\
\left(\mathrm{cm}^{2} / \mathrm{s}\right)\end{array}$ & $1.3 \times 10^{-6}$ & $\begin{array}{c}\text { McAllister et al. } \\
(2003)\end{array}$ \\
\hline Volume of distribution: $\mathrm{V}_{\mathrm{b}}(\mathrm{ml})$ & 21000 & Van Rossum (1977) \\
\hline Elimination rate constant: $\mathrm{K}_{\mathrm{e}}\left(\mathrm{s}^{-1}\right)$ & $1.27 \times 10^{-4}$ & Van Rossum (1977) \\
\hline Skin surface concentration: $\mathrm{C}_{\mathrm{s}}(\mu \mathrm{g} / \mathrm{ml})$ & 4.17 & Davis (2003) \\
\hline Microneedle length: $\mathrm{L}(\mathrm{cm})$ & 0.01 & Teo et al. (2005) \\
\hline Number of microneedles: $\mathrm{n}(-)$ & 13 & - \\
\hline Microneedle radius: $\mathrm{R}(\mathrm{cm})$ & 0.0115 & - \\
\hline
\end{tabular}




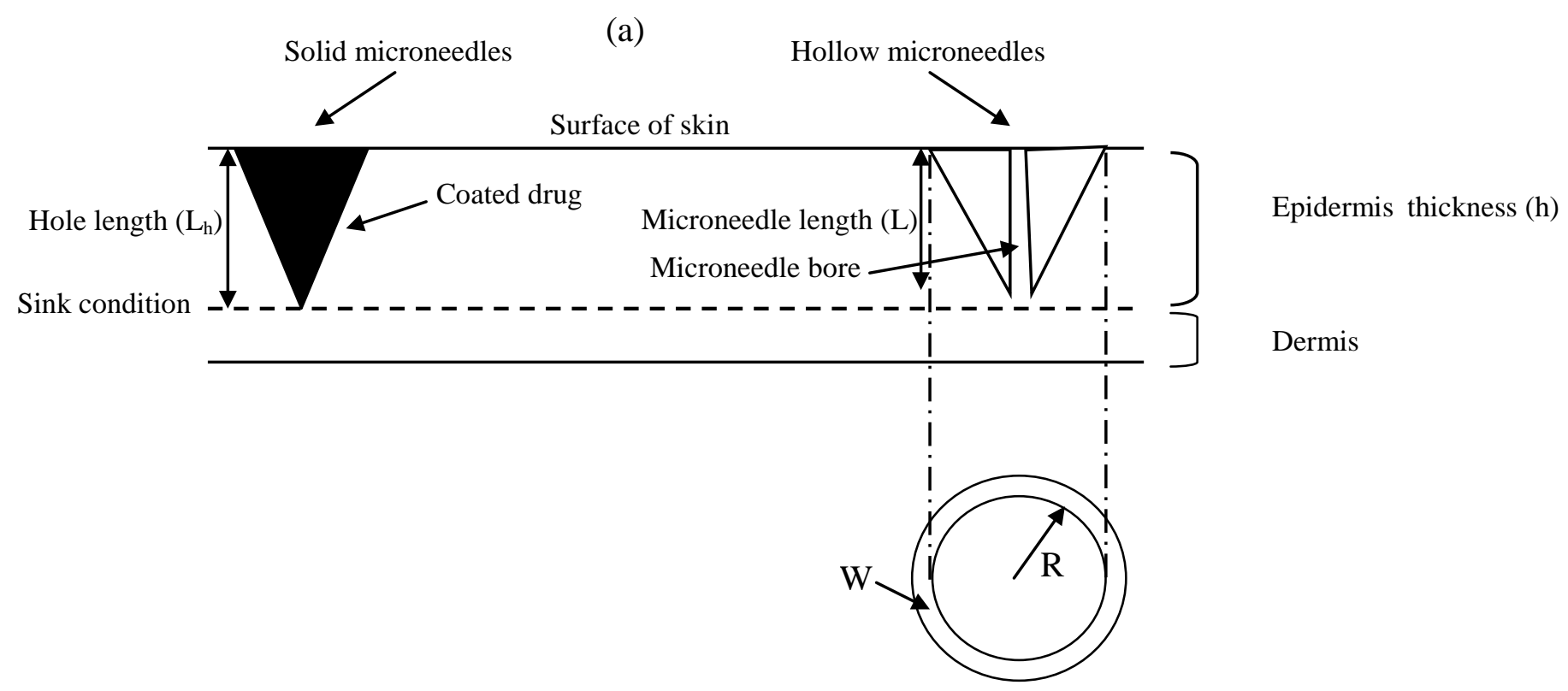

(b)

Figure 1. The Schematic diagram of solid and hollow microneedles (a) side view, (b) top view ( $\mathrm{W}$ is the annular gap width, $\mathrm{R}$ is microneedle radius). 


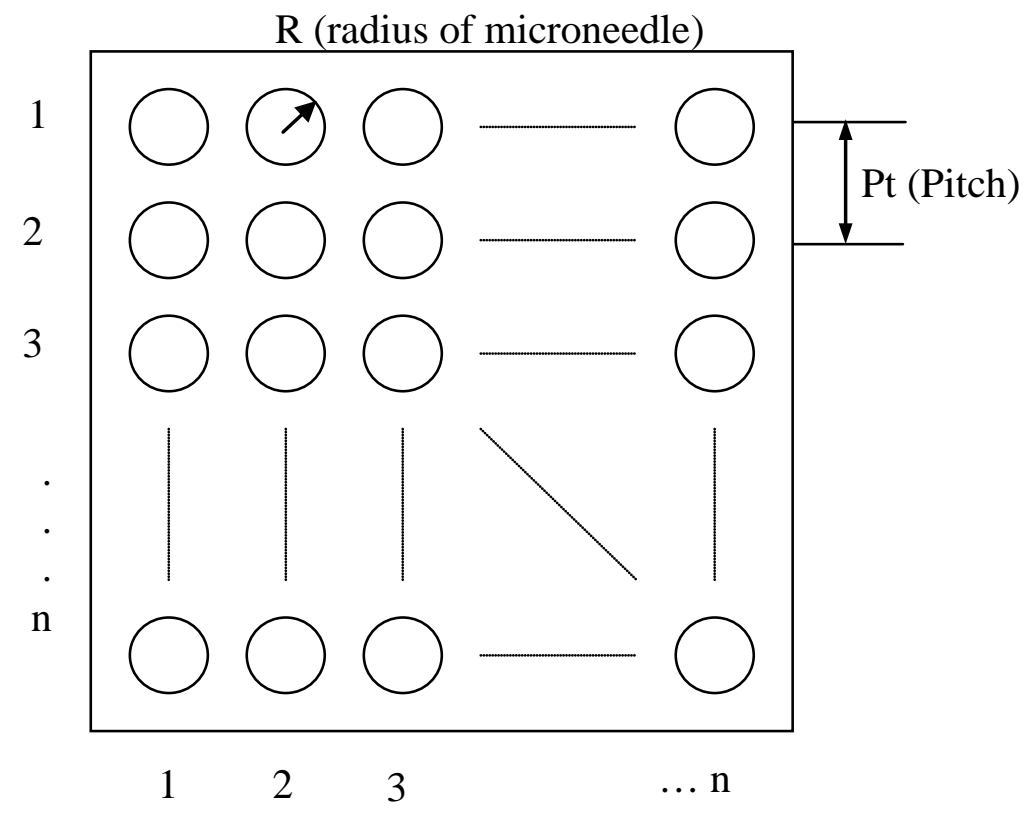

Figure 2. The Schematic diagram of a square patch of microneedle array (top view) 
Microneedle System Optimization

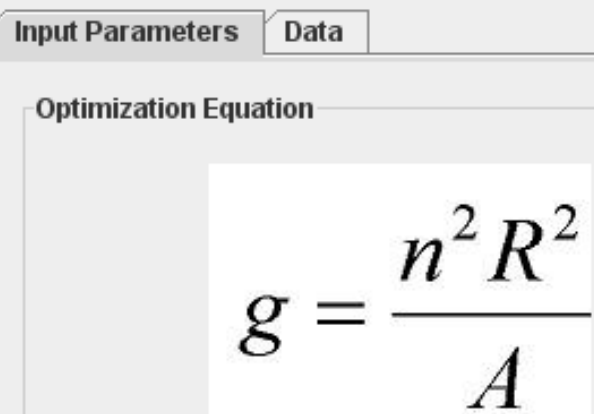

Optimization Parameters Constraints

\begin{tabular}{|c|c|c|c|c|}
\hline 4 & $\leq \mathbf{n} \leq$ & 20 & scale & 1 \\
\hline 40 & $\leq R \leq$ & 150 & scale & 5 \\
\hline 0.04 & $\leq A \leq$ & 0.56 & scale & 0.01 \\
\hline
\end{tabular}

Constraints Equations

$n_{\min } \leq n \leq n_{\max }$

$R_{\min } \leq R \leq R_{\max }$

$A_{\text {min }} \leq A \leq A_{\text {max }}$

$\frac{\sqrt{A}}{n} \geq \alpha R$

Optimize!

Opitimzation Result

$\mathbf{n}=\mathbf{1 7}$

$R=110$

$A=0.14$

at $\mathrm{g}=0.2498$

Figure 3. Graphical user interface of in-house Java program used for microneedles system optimization. 


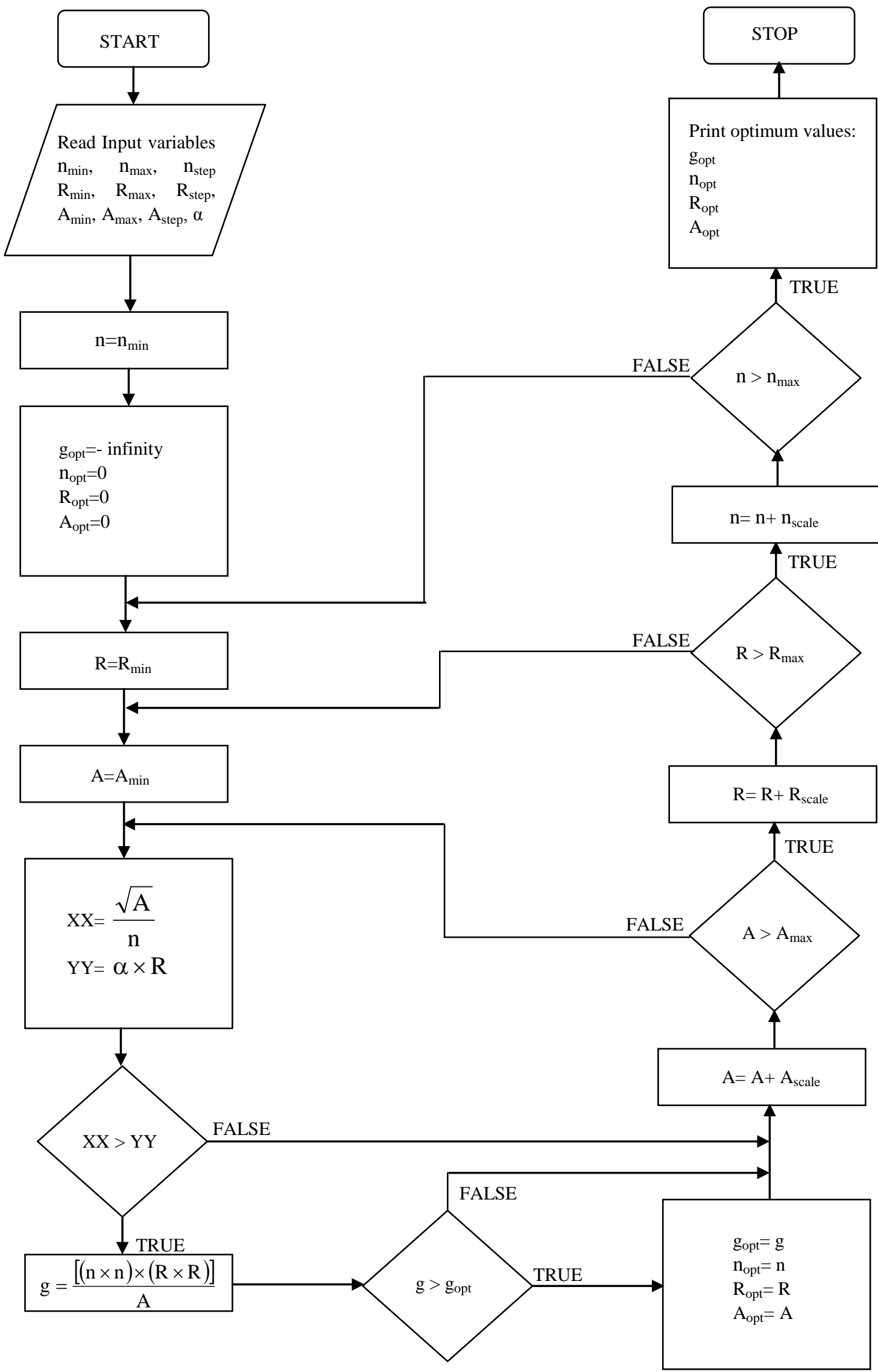

Figure 4. Algorithm used in Java program (Figure 2) for microneedles system optimization. 


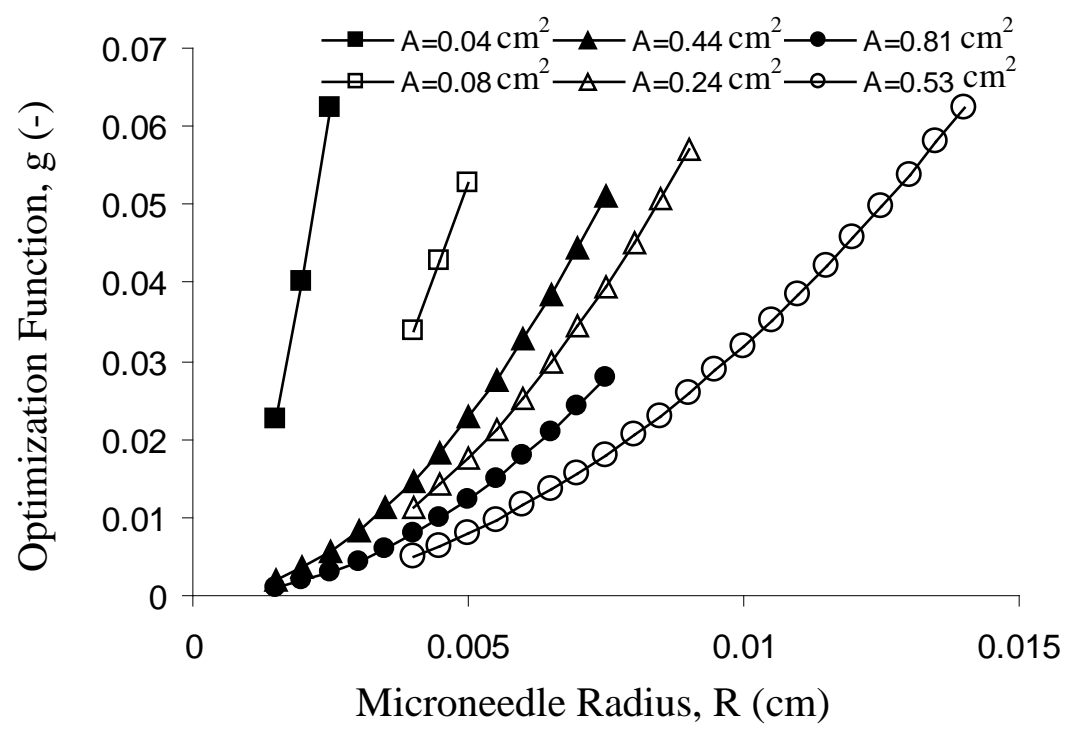

Figure 5. Influence of the surface area of the patch (A) of solid (dark points) and hollow (light points) microneedles on optimization function (g), (number of microneedles per row (n) =20, 13 for solid and hollow microneedles, respectively, aspect ratio $(\alpha)=4)$. 


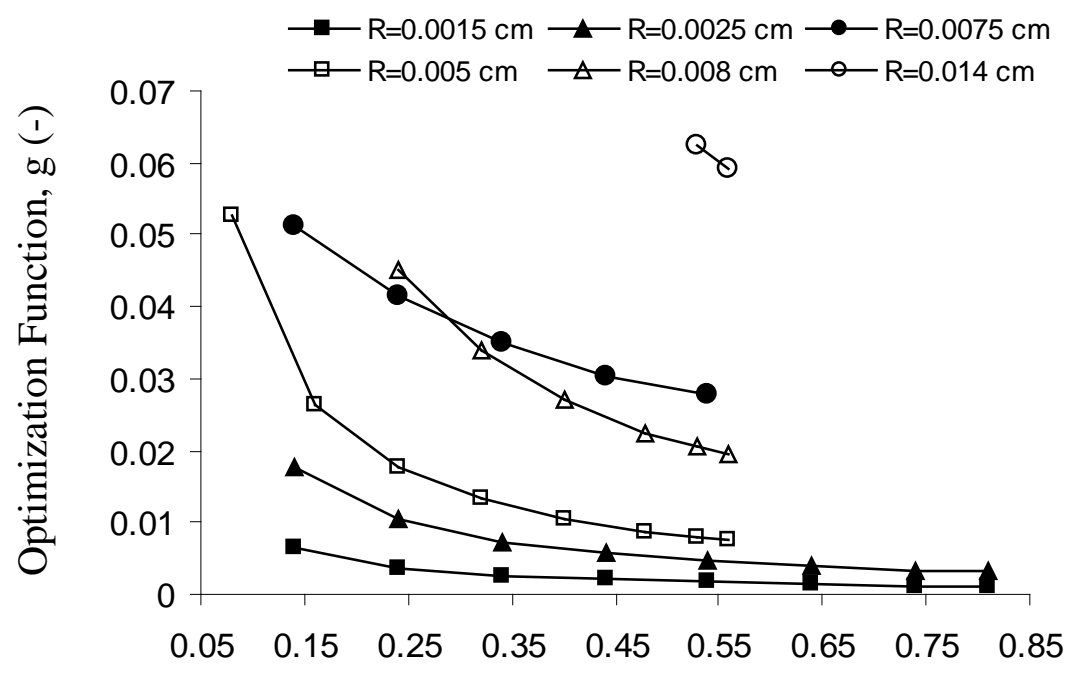

Surface Area of the Patch, A $\left(\mathrm{cm}^{2}\right)$

Figure 6. Influence of the microneedle radius (R) of solid (dark points) and hollow (light points) microneedles on the optimization function (g), (number of microneedles per row $(n)=20,13$ for solid and hollow microneedles, respectively, aspect ratio $(\alpha)$ $=4)$. 


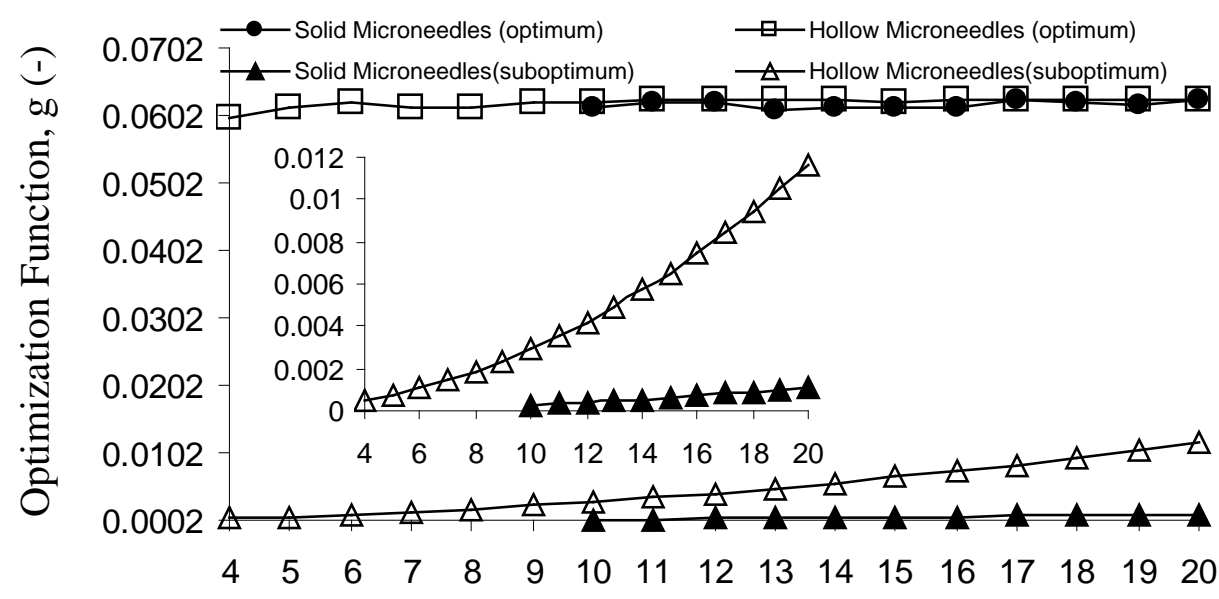

Number of Microneedles per row, n (-)

Figure 7. Influence of the optimum/suboptimum number of microneedles per row (n) for solid (dark points) and hollow (light points) microneedles on the optimization function $(\mathrm{g})$ for parameters as shown in Table 2 , (aspect ratio $(\alpha)=4)$. 


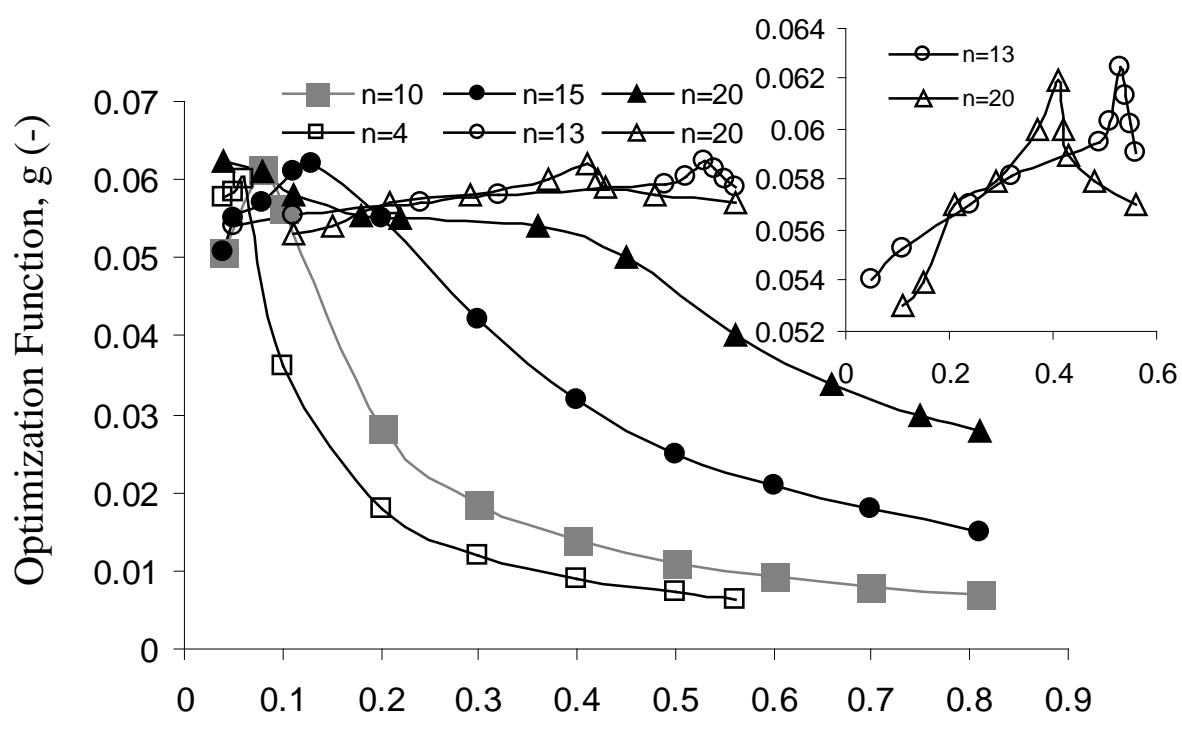

Surface Area of the Patch, A $\left(\mathrm{cm}^{2}\right)$

Figure 8. Influence of the number of microneedles per row (n) for solid (dark points) and hollow (light points) microneedles with their optimum radii on the optimization function $(\mathrm{g})($ aspect ratio $(\alpha)=4)$. 


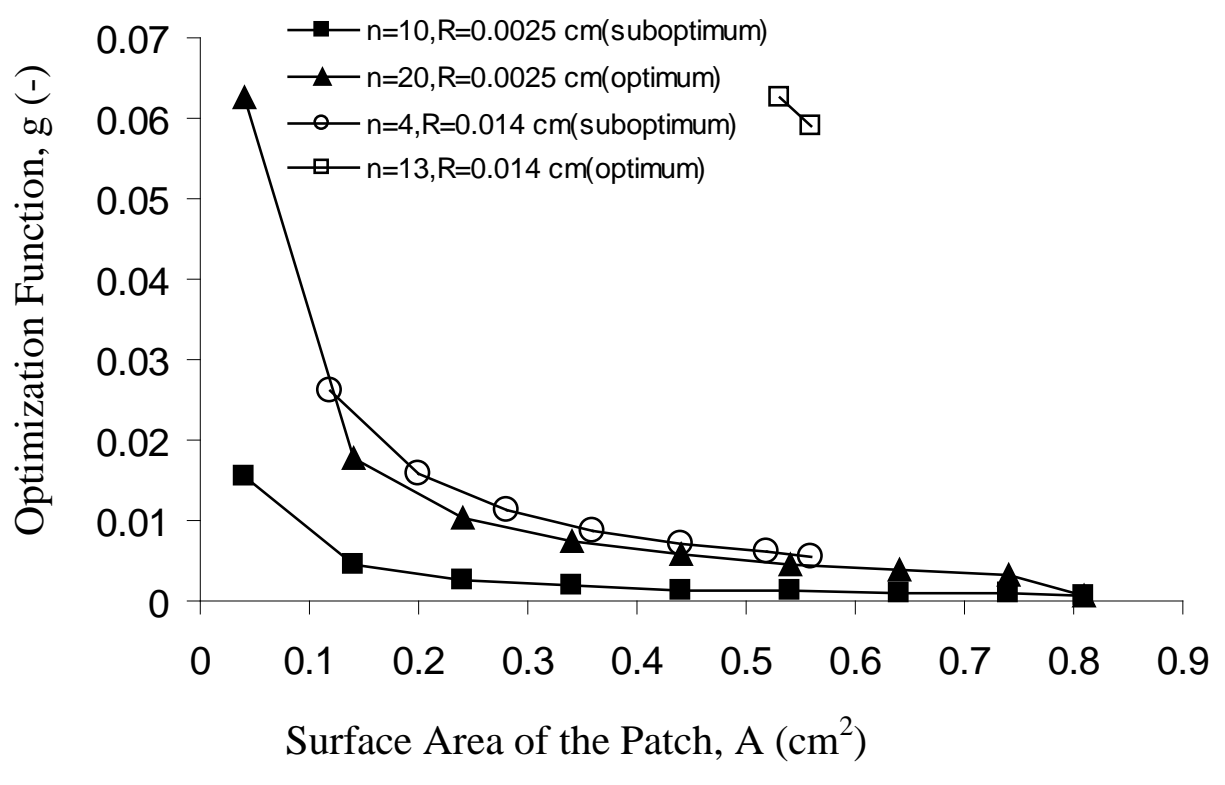

Figure 9. Influence of optimum/suboptimum number of microneedles per row (n) for solid (dark points) and hollow (light points) microneedles with their optimum/suboptimum radius on the optimization function $(\mathrm{g})$ (aspect ratio $(\alpha)=4)$. 


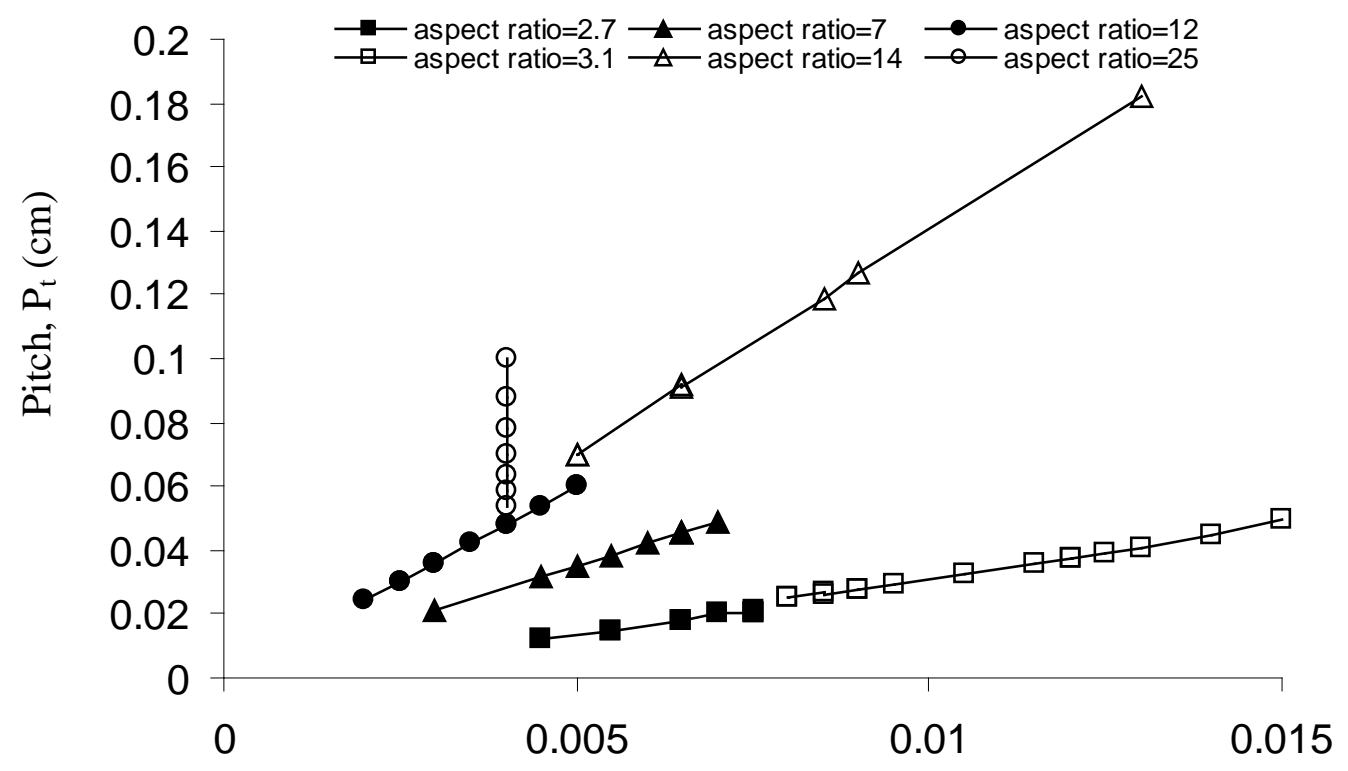

Microneedle Radius, R (cm)

Figure 10. Influence of the aspect ratio of pitch over microneedle radius $(\alpha)$ of solid (dark points) and hollow (light points) microneedles on the optimum pitch $\left(\mathrm{P}_{\mathrm{t}}\right)$ for various number of microneedles per row (n). 


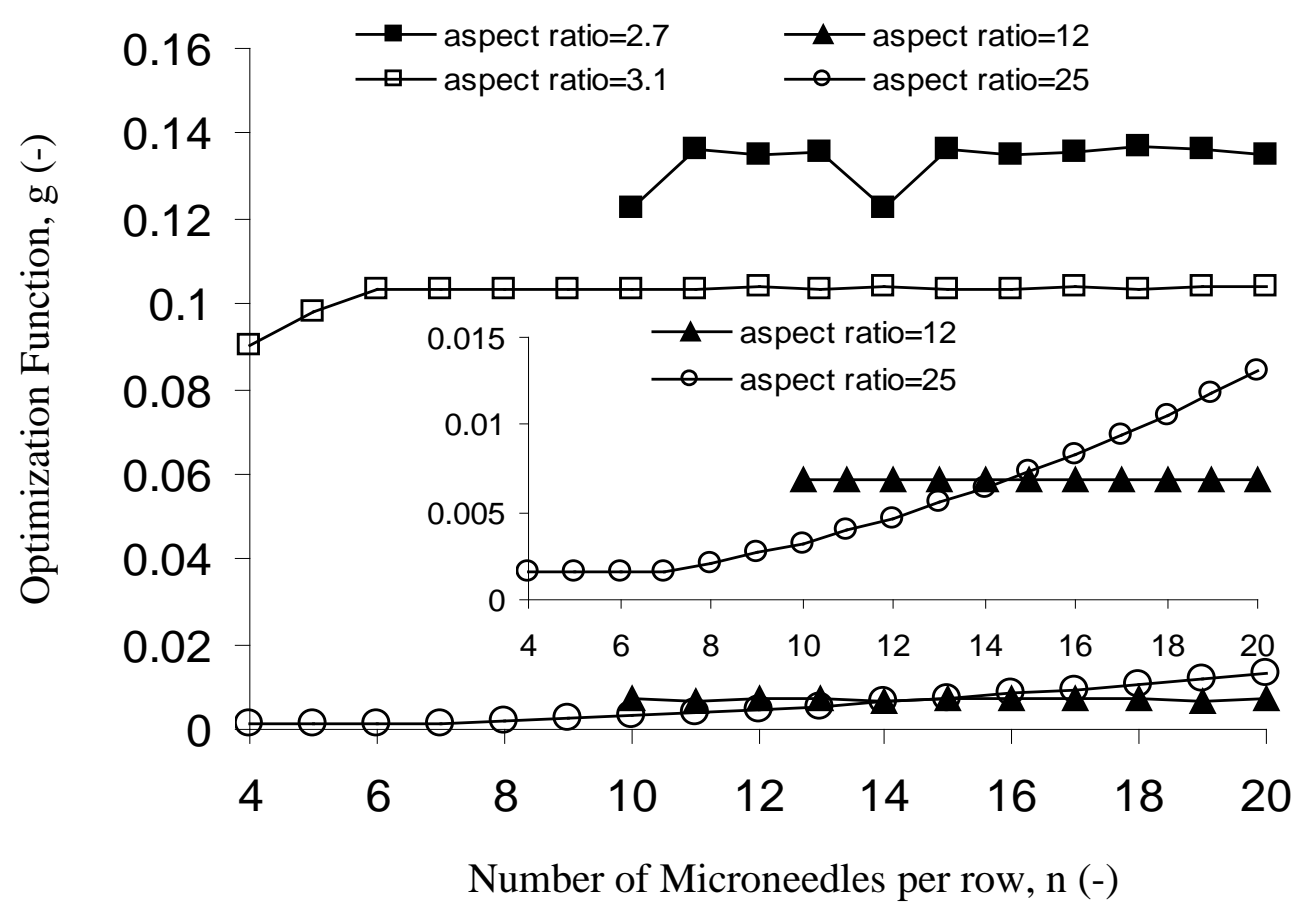

Figure 11. Influence of the aspect ratio of pitch over microneedle radius $(\alpha)$ of solid (dark points) and hollow (light points) microneedles on our optimization function (g) for various number of microneedles per row (n). 


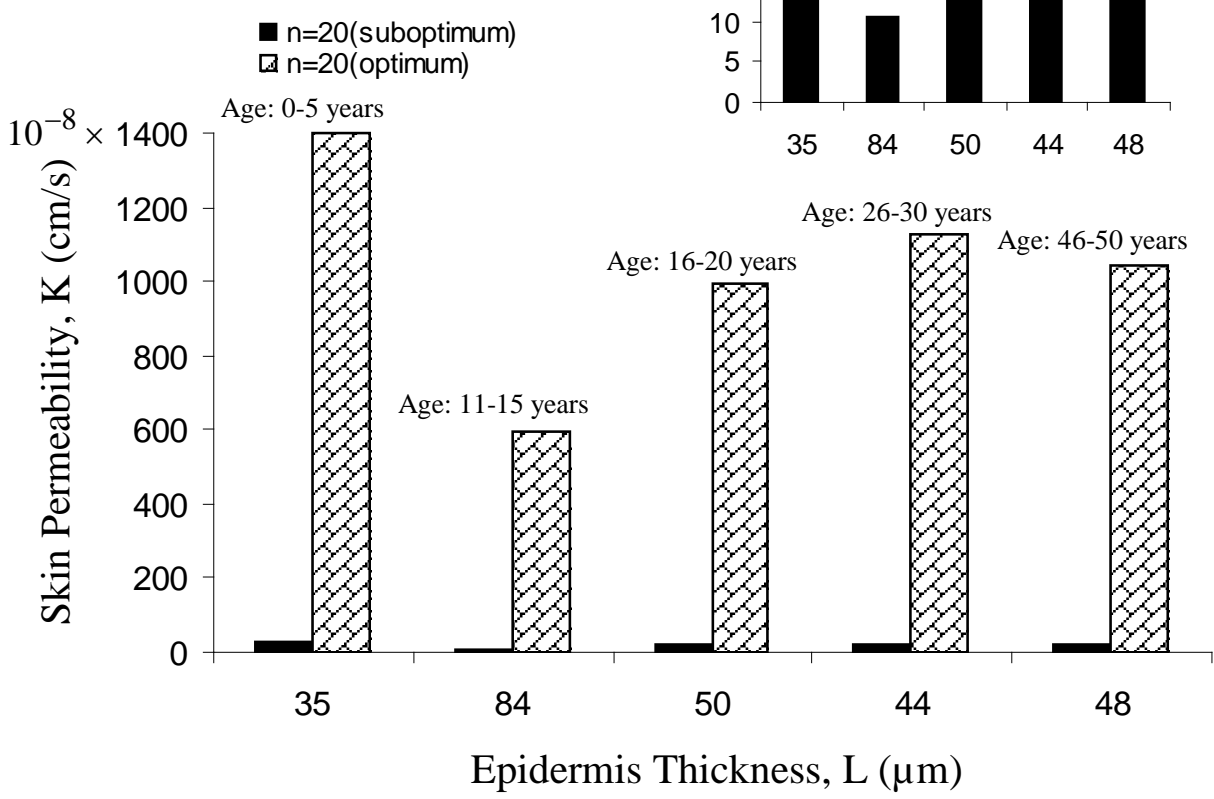

Figure 12. Influence of epidermis thickness (h) of optimum/suboptimum numbers of microneedles per row (n) for solid microneedles for various groups age on skin permeability (K). 


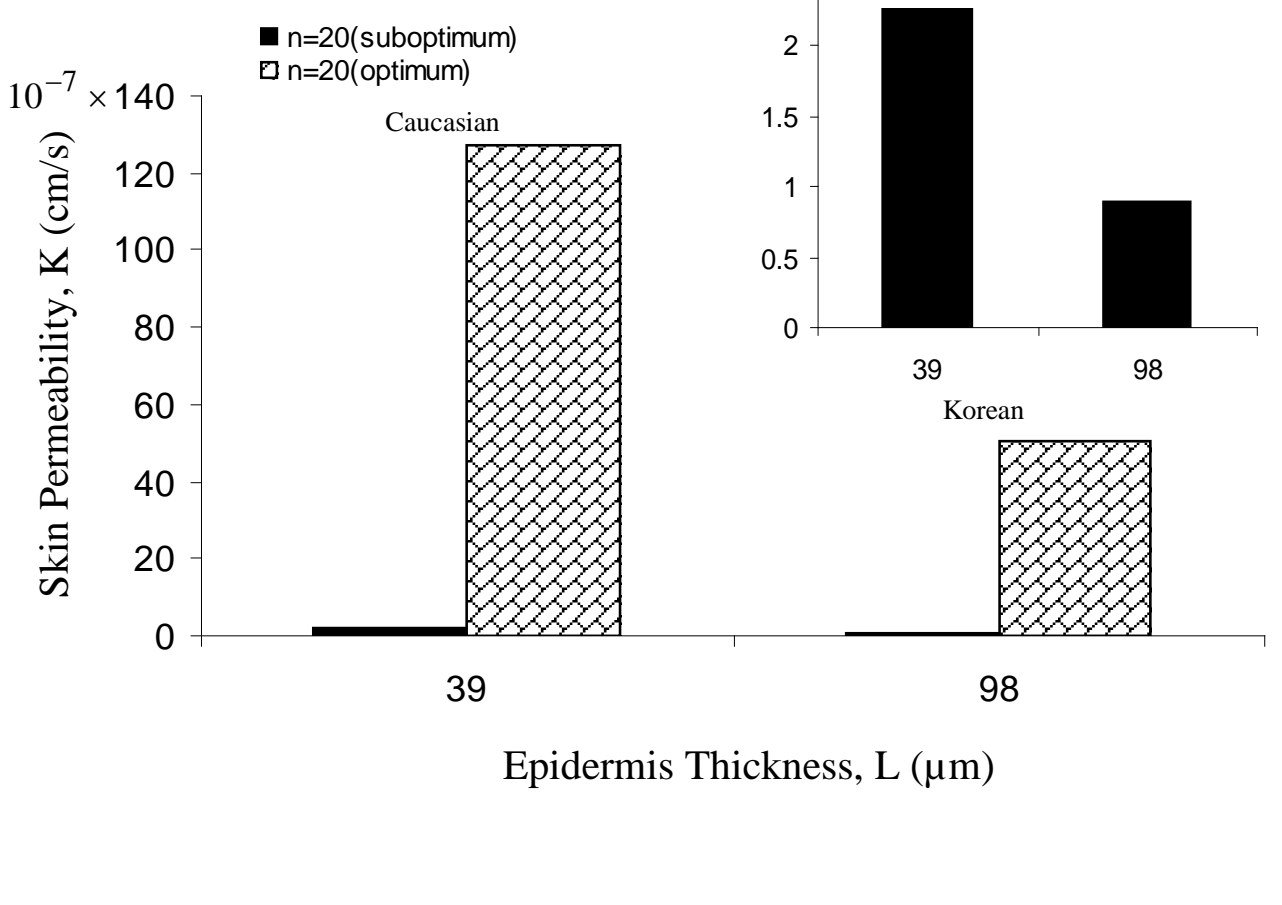

Figure 13. Influence of epidermis thickness (h) of optimum/suboptimum numbers of microneedles per row (n) for solid microneedles for different races on skin permeability (K). 


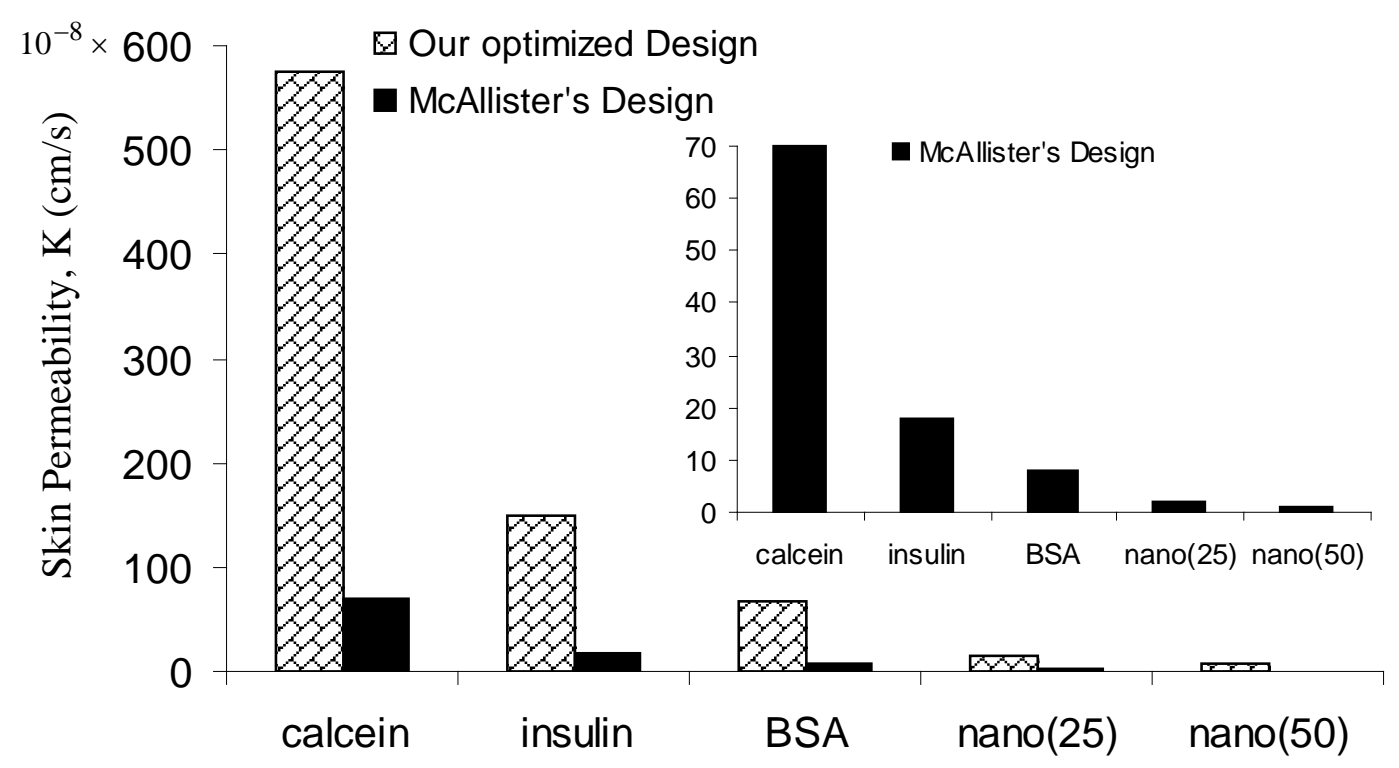

Figure 14. Influence of applying our optimization model in skin permeability (K) for different drugs (i.e., insulin is hexameric insulin, nano(25) and nano(50) are nanosphere particles with molecular radii of $25 \mathrm{~nm}$ and $50 \mathrm{~nm}$, respectively). 


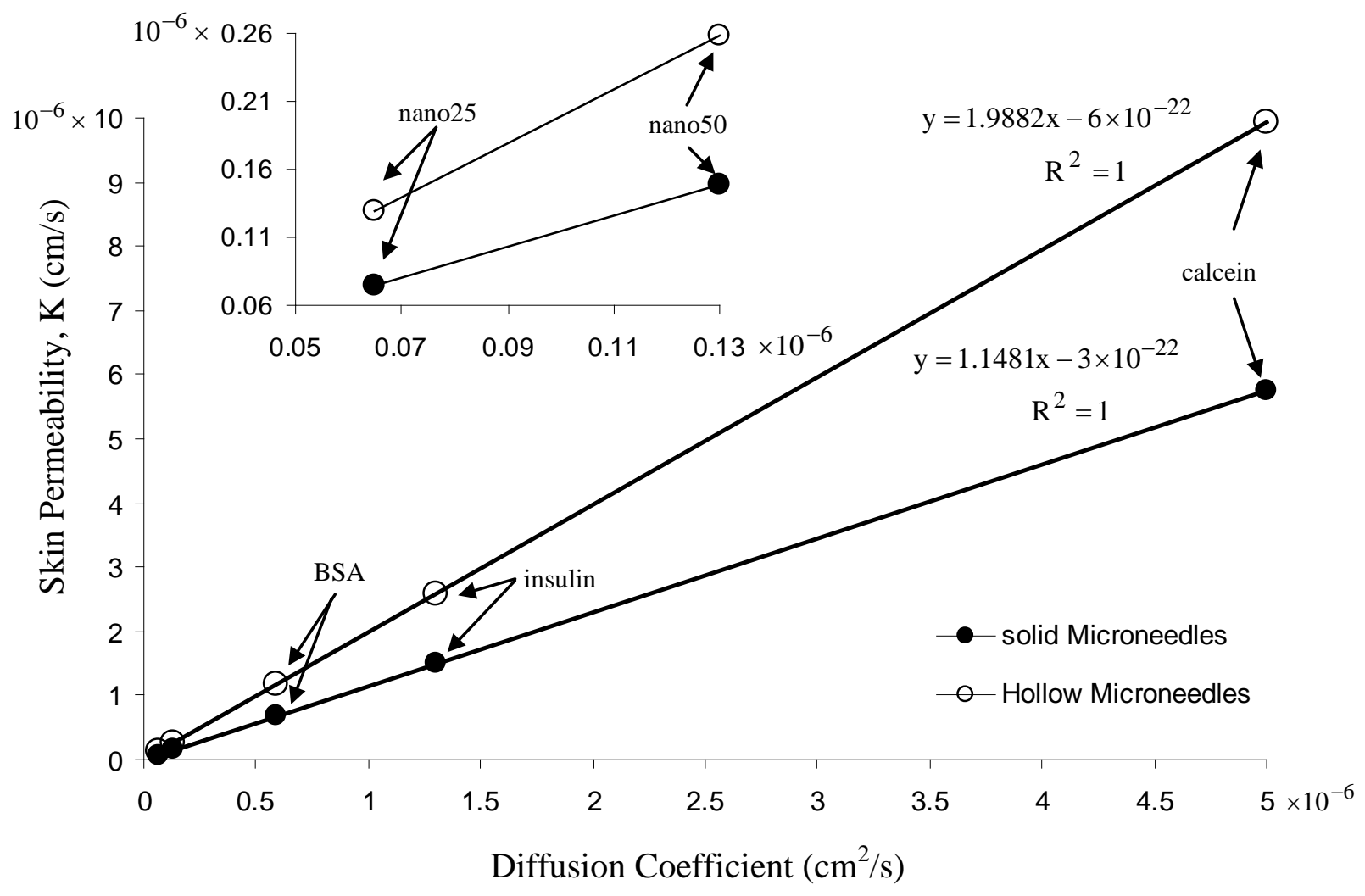

Figure 15. Relationship between skin permeability (K) and diffusion coefficient (D) of the optimum solid $\left(\mathrm{n}=20, \mathrm{R}=19 \mu \mathrm{m}\right.$ and $\left.\mathrm{A}=0.04 \mathrm{~cm}^{2}\right)$ and hollow $(\mathrm{n}=13, \mathrm{R}=14 \mu \mathrm{m}$ and $\mathrm{A}=0.53 \mathrm{~cm}^{2}$ ) microneedles for various drugs (i.e., calcein, insulin, BSA (bovine serum albumin), nano25 and nano50 (nanosphere particles with radii of $25 \mathrm{~nm}$ and 50 $\mathrm{nm}$, respectively)). 


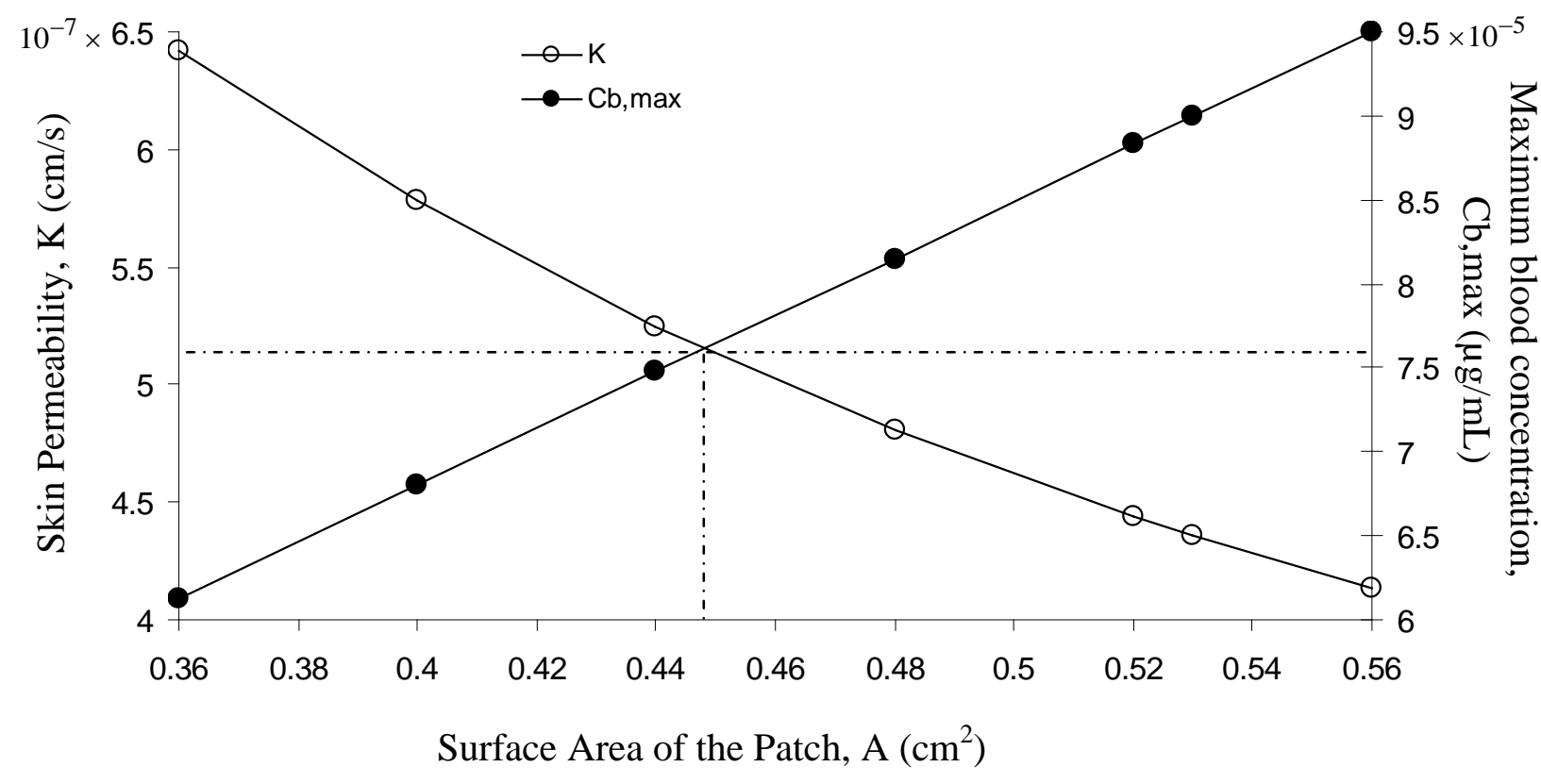

Figure 16. The optimum point (intercept) between skin permeability (K) and maximum blood drug concentration (Cb,max) of the optimum hollow microneedles $(\mathrm{n}=13$ and $\mathrm{R}=115 \mu \mathrm{m}$ ) with various surface area of patch for insulin as a model drug. 